\author{
UNIVERSIDADE DE SÃO PAULO \\ FACULDADE DE CIÊNCIAS FARMACÊUTICAS DE RIBEIRÃO PRETO
}

\title{
Avaliação in vitro e in vivo da atividade fotoquimioprotetora da fração de Byrsonima crassifolia e da (+)-catequina contra os danos induzidos pela radiação UVB
}

Tese de doutorado apresentada ao Programa de Pós-Graduação em Ciências Farmacêuticas para obtenção do Título de Doutor em Ciências.

Área de concentração: Medicamentos e Cosméticos.

Orientada: Rebeca Oliveira de Souza

Orientadora: Prof $^{\mathrm{a}}$. Dr ${ }^{\mathrm{a}}$ Maria José Vieira Fonseca

Versão corrigida da Tese de Doutorado Direto apresentada ao Programa de PósGraduação em Ciências Farmacêuticas no dia 02/04/2015. A versão original encontra-se disponível na Faculdade de Ciências Farmacêuticas de Ribeirão Preto/USP.

Ribeirão Preto 


\section{RESUMO}

SOUZA, R. O. Avaliação in vitro e in vivo da atividade fotoquimioprotetora da fração de Byrsonima crassifolia e da (+)-catequina contra os danos induzidos pela radiação UVB. 2015. 140f. Tese (Doutorado) Faculdade de Ciências Farmacêuticas, Universidade de São Paulo, 2015.

A pele é o maior tecido do corpo humano e está constantemente exposta a inúmeros agentes nocivos, dentre os quais se destaca a radiação ultravioleta (RUV), que está relacionada aos fotodanos do DNA, geração de espécies reativas de oxigênio (EROs) e ativação de mediadores do processo inflamatório. Nestas circunstâncias, mesmo possuindo um sistema de defesa antioxidante, a pele é submetida ao estresse oxidativo devido ao aumento da concentração de radicais livres, o que rompe o equilíbrio próoxidante/antioxidante. Neste contexto, as substâncias naturais tem sido frequentemente empregadas como ferramenta para enriquecer o sistema protetor cutâneo endógeno, reduzindo, dessa forma, os danos oxidativos causados pela RUV na pele. Sendo assim, o presente trabalho teve como objetivo avaliar o efeito fotoquimioprotetor in vitro e in vivo da fração de média polaridade de Byrsonima crassifolia $(\mathrm{BC})$ e da (+) catequina (CAT), em cultura de queratinócitos humanos e em camundongos sem pelos submetidos à radiação UVB. Comparado ao extrato purificado, a fração de BC apresentou elevada atividade antioxidante in vitro e maiores teores de polifenóis totais e de compostos fenólicos: (+) catequina ( $255 \pm 3,2 \mathrm{mg} / \mathrm{g}$ de fração), (-) epigalocatequina-3-galato (26 \pm $1,68 \mathrm{mg} / \mathrm{g}$ de fração) e quercetina 3-O- $\beta$-D-glicopiranosídeo $(12 \pm 0,09 \mathrm{mg} / \mathrm{g}$ de fração). A formulação gel adicionada da fração de BC $(1 \%)$ proporcionou maior liberação dos compostos fenólicos na pele de orelha de porco do que a formulação emulgel e a CAT foi o composto fenólico majoritário quantificado na epiderme viável da pele de orelha de porco $\left(21,72 \pm 5,2 \mu \mathrm{g} / \mathrm{cm}^{2}\right)$. Dessa forma, a formulação gel $(1 \%)$ adicionada da fração de $\mathrm{BC}$ ou CAT foi avaliada também quanto à penetração cutânea in vivo. Na epiderme viável da pele dos camundongos sem pelos detectou-se os compostos fenólicos da fração de BC, bem como a CAT. A avaliação fotoquimioprotetora da fração de BC e da CAT em cultura de queratinócitos demonstrou que ambas as amostras foram capazes de inibir a peroxidação lipídica, a secreção da IL-6 e a redução do NFkB/p65 no citoplasma induzidos pela radiação UVB. Em relação à atividade fotoquimioprotetora in vivo, a fração de BC e CAT foram capazes de evitar/diminuir a depleção dos níveis de GSH, o infiltrado inflamatório e a secreção das citocinas IL-1 $\beta$ e IL-6 induzidos pela radiação UVB. Por outro lado, somente a fração de $\mathrm{BC}$ foi capaz de inibir a atividade/secreção da metaloproteinase MMP-9, o que demonstra uma potente atividade fotoquimioprotetora e sugere que o efeito da fração vegetal pode ser superior ao do padrão (+) CAT, já que a fração é composta por uma mistura complexa de substâncias capazes de potenciar a ação dos polifenóis. Estes resultados são promissores e apontam para o uso da fração de BC e da CAT na prevenção/tratamento dos danos induzidos pela radiação UVB na pele.

Palavras-chave: Antioxidantes, Byrsonima crassifolia, Catequina, Radiação UV, Fotoquimioproteção, Queratinócitos, Camundongos sem pelos e Penetração cutânea. 
Introdução e Revisão da Literatura 1

1 Introdução e Revisão da Literatura 


\subsection{Características da Pele}

A pele é o maior órgão do corpo humano e dispõe de uma área superficial de aproximadamente 1,5-2,0 $\mathrm{m}^{2}$, atuando como uma barreira eficaz contra os efeitos nocivos de agentes ambientais e regulando a perda de água, além de proteger os órgãos internos do corpo. Anatomicamente, a pele humana é composta por três camadas: uma camada superior, a epiderme, uma intermediária, a derme e uma mais profunda, a hipoderme, como mostra a figura 1(Nichols e Katiyar, 2010; Wertz, 2013; Natarajan et al., 2014).

A epiderme consiste de um epitélio estratificado, queratinizado e escamoso, no qual $80 \%$ das células são queratinócitos, principais células responsáveis pela produção de citocinas epidérmicas (Grone, 2002). Outros tipos de células incluem melanócitos (síntese do pigmento), células de Langerhans (função imunológica) e células de Merkel (função de receptor). A epiderme humana é constituída por cinco camadas distintas sendo elas, da mais interna para a mais externa (Svobodova e Vostalova, 2010) (figura 1):

- Camada basal da epiderme é a camada mais interna e é responsável pela renovação contínua da epiderme, sendo formada por células jovens que separam a epiderme da derme. Após as células basais sofrerem mitose, novos queratinócitos são gerados, os quais migram para cima empurrando as células existentes para a superfície externa;

- Camada espinhosa é formada por células que apresentam projeções citoplasmáticas (desmossomos e filamentos de queratina) e ancoram as células umas às outras, dando resistência ao atrito;

- Camada granulosa é composta por células poligonais achatadas e têm grânulos de querato-hialina em seu citoplasma, que são precursores da queratina do estrato córneo;

- Camada lúcida é mais evidente na pele espessa (palma das mãos e planta dos pés) e é constituída por uma delgada camada de células achatadas e translúcidas, cujos núcleos e organelas citoplasmáticas foram digeridos por enzimas dos lisossomos e desapareceram.

- Camada córnea ou estrato córneo é a camada mais externa da epiderme, funciona como barreira física e química, sendo composta de células queratinizadas mortas desprovidas de núcleos. Estas células são chamadas de corneócitos e são o produto final dos queratinócitos. Dentro dos corneócitos são encontradas substâncias hidrofílicas de baixa massa molecular como aminoácidos, açúcares e queratina, que fornecem resistência a estas células. Cada corneócito do estrato córneo é envolto por um envelope protéico e entre eles está presente a maioria do material lipídico na forma de lipídeos neutros. As células queratinizadas são embebidas em uma matriz lipídica organizada em bicamadas ricas em ceramidas, colesterol e ácidos graxos livres. 
A derme é um tecido conjuntivo denso que apóia a epiderme e une a pele ao tecido celular subcutâneo ou hipoderme. A derme e epiderme são interligadas por papilas dérmicas e epidérmicas, compostas principalmente por fibras de colágeno e elastina, que conferem elasticidade à pele. As principais células da derme são os fibroblastos, além de mastócitos, macrófagos, adipócitos e células plasmáticas. O tecido está entrelaçado com fibras nervosas, vasos sanguíneos e linfáticos que alimentam a epiderme. Os fibroblastos são células fusiformes ou estreladas que sintetizam as fibras dérmicas. As fibras dérmicas conferem resistência mecânica à pele, e são constituídas, em sua maioria por colágeno intersticial, principalmente de tipos I e III, porém outros tipos de colágenos são encontrados na derme como os colágenos do tipo IV e VII (Kanitakis, 2002). A camada subcutânea, denominada hipoderme, atua como reserva energética, proteção contra choques mecânicos e isolamento térmico (Junqueira e Carneiro, 2004).

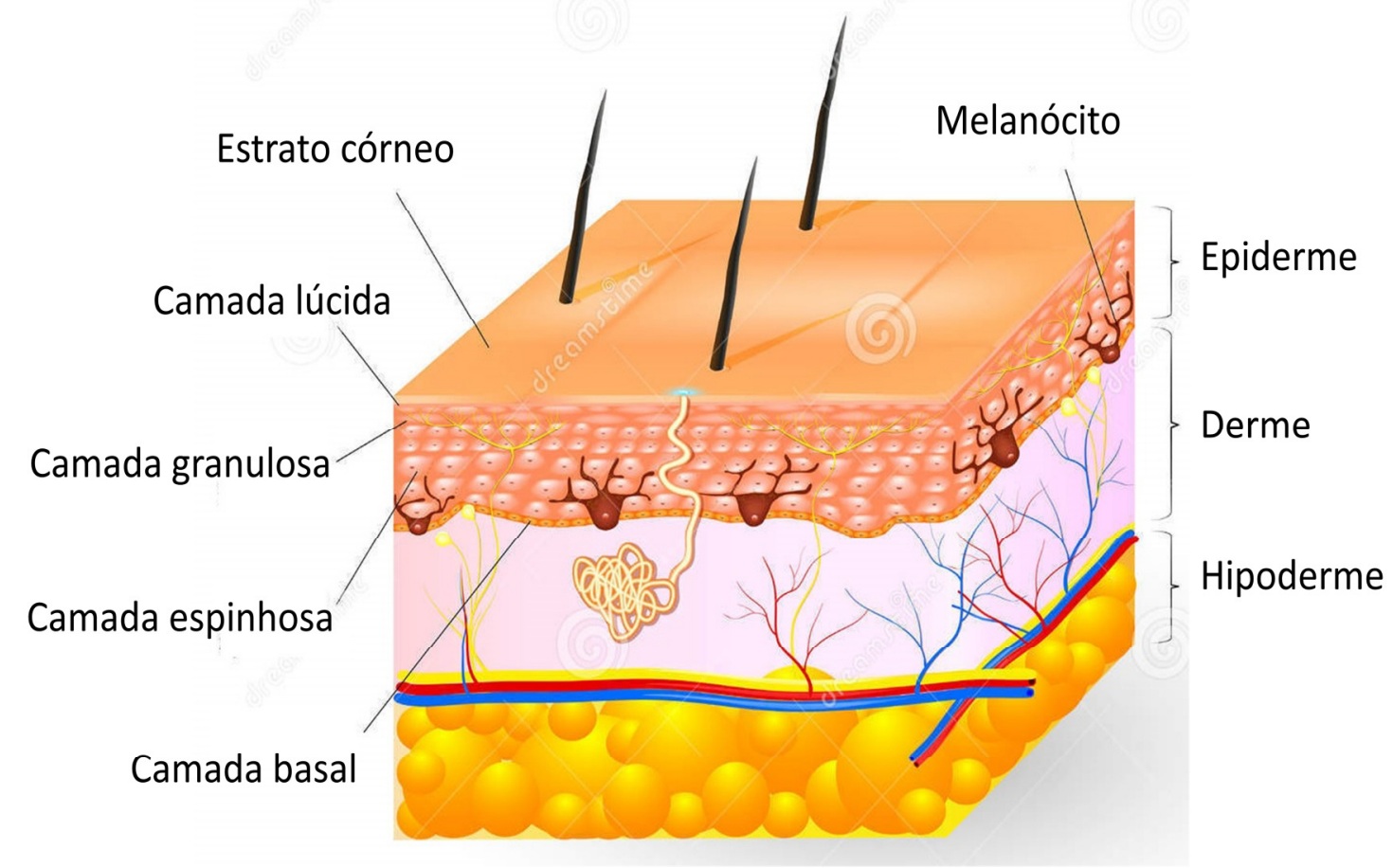

Figura 1 : Camadas da pele humana: epiderme (estrato córneo, camada lúcida, camada granulosa, camada espinhosa e camada basal), derme e hipoderme. Adaptado de imagem disponível em <http://www.skin-remedies.com/skin.html>. Acesso em Janeiro de 2015.

A pele apresenta interações celulares e moleculares reguladas, que governam de modo preciso muitas das agressões provindas do meio ambiente. Ela oferece um sistema de defesa antioxidante endógeno, constituído por antioxidantes não enzimáticos e os enzimáticos. $\mathrm{O}$ grupo dos antioxidantes não enzimáticos inclui os carotenóides, a vitamina $\mathrm{C}$ (ácido 
ascórbico), a vitamina E ( $\alpha$-tocoferol), ubiquinol-10 (coenzima Q10) e outras substâncias como cisteína, ácido úrico e glutationa reduzida (GSH), além de substâncias quelantes de íons metálicos. Os antioxidantes enzimáticos incluem enzimas como a superóxido dismutase (SOD), a catalase (CAT), mieloperoxidase (MPO), a glutationa redutase e a glutationa peroxidase que detoxificam os radicais peróxidos, peróxido de hidrogênio e hidroperóxidos lipídicos. Entre estas enzimas, a SOD e a CAT são as principais enzimas antioxidantes que protegem a epiderme. A SOD converte ânions superóxido em peróxido de hidrogênio $\left(\mathrm{H}_{2} \mathrm{O}_{2}\right)$, enquanto a CAT degrada $\mathrm{H}_{2} \mathrm{O}_{2}$ em água e oxigênio (Shindo, Witt e Packer, 1993; Sander et al., 2002; F'guyer, Afaq e Mukhtar, 2003; Sander et al., 2004; Peres et al., 2011).

Estes sistemas de defesa antioxidante estão em maior concentração na epiderme, indicando ser esta mais susceptível do que a derme ao estresse oxidativo (Shindo et al., 1994). Desta forma, torna-se relevante a utilização de células presentes na epiderme, como queratinócitos, para estudos que objetivam avaliar o estresse oxidativo na pele.

\subsection{A radiação ultravioleta e os danos causados à pele}

O sol emite principalmente luz visível e radiação infravermelha, mas também emite radiação ultravioleta (UV), a qual será o foco do presente trabalho. A exposição excessiva à radiação UV é capaz de limitar a capacidade natural dos sistemas de defesa da pele, propiciando a iniciação de várias perturbações à pele, tais como fotoenvelhecimento, imunossupressão sistêmica, inflamação aguda e em última fase o câncer de pele. A radiação UV é dividida em três faixas dependendo do comprimento de onda: UVC (200-290 nm), UVB (290-320 nm), e UVA (320- 400 nm) (Mukhtar e Elmets, 1996; Xu e Fisher, 2005; Guaratini, Medeiros e Colepicolo, 2007)

A forma de radiação ultravioleta mais energética é a UVC, que não chega à superfície terrestre, pois é absorvida pela camada de ozônio. A radiação UVB representa 5\% da radiação ultravioleta que alcança a superfície terrestre e a radiação UVA 95\% (Svobodova, Walterova e Vostalova, 2006). A radiação UVB é o componente mais prejudicial da radiação solar que atinge a superfície da terra, pois é capaz de induzir uma série de danos à pele humana, sendo menos penetrante e mais genotóxica e mutagênica do que a radiação UVA e atuando principalmente na camada epidérmica da pele. Embora a radiação UVA seja menos energética, é a que mais atinge a Terra e possui o maior potencial penetrante, sendo que o seu principal modo de ação se dá pela geração de espécies reativas de oxigênio (EROs); por outro lado, a radiação UVA estimula a formação da melanina e protege a pele de queimaduras imediatas (figura 2) (Abu Zaid et al., 2007; Maverakis et al., 2010). 


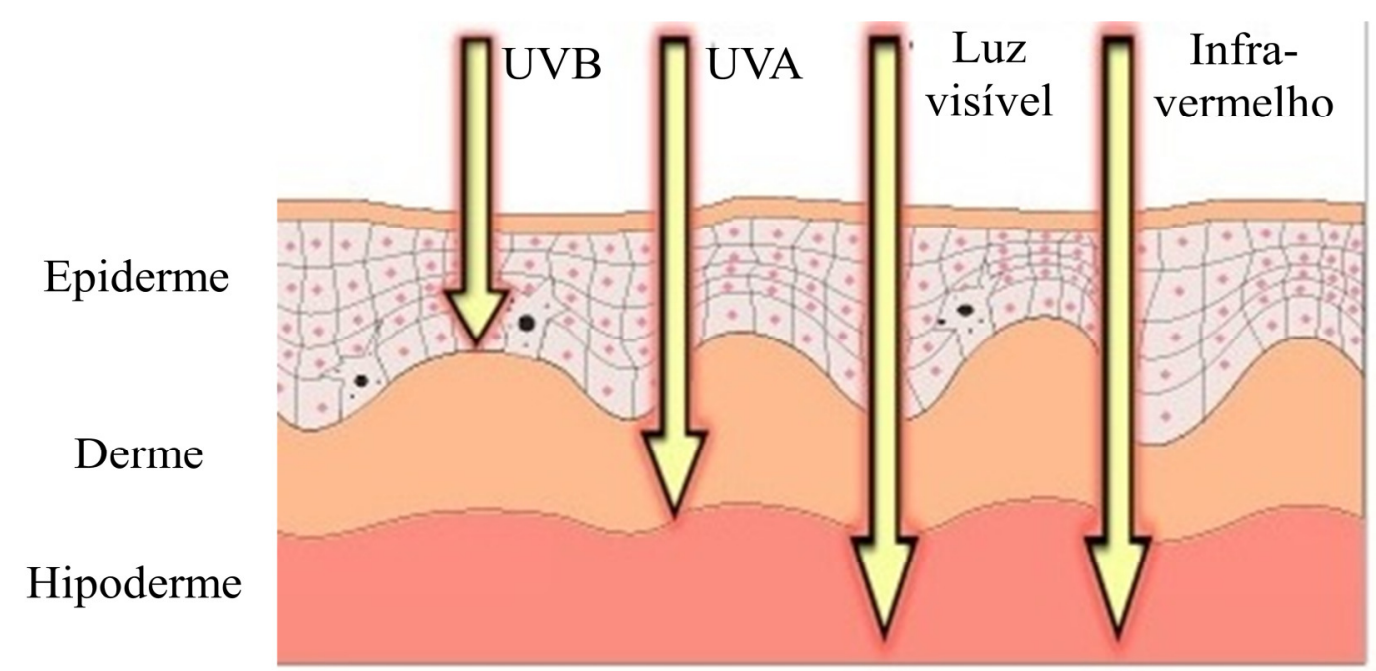

Figura 2: Capacidade de penetração da radiação solar na pele humana em função do comprimento de onda. Adaptado de: $<$ http://www.industrial-needs.com/technicaldata/radiation-meter-PCE-UV34.htm>. Acesso em: janeiro de 2015.

O efeito mais específico da exposição da pele humana à radiação UVB é representado por danos no DNA, devido à interação da radiação com as bases heterocíclicas, o que induz a formação de dímeros de pirimidina ciclobutano (CPD) e fotoprodutos pirimidina-pirimidona (6-4). Os danos são causados pela ligação errônea de duas pirimidinas na mesma fita de DNA. Em vez de ocorrer o pareamento clássico (Adenina-Timina) AT ou GC (Guanina-Citosina), as bases podem ligar-se por meio de CC, TT ou CT (Heck et al., 2004; Cadet, Sage e Douki, 2005).

Para manter a integridade das células após danos no DNA várias respostas celulares são induzidas, como a ativação transcricional do gene $p 53$, que desempenha papel direto no reparo do DNA ou indução da apoptose (Levine, 1997; Smith e Fornace, 1997; Kamijo et al., 1998; Lu et al., 1999). A proteína p53 é ativada por fosforilação devido ao aumento da transcrição do gene supressor de tumor p53 (Matsumura e Ananthaswamy, 2004). Desta forma, o aumento do nível da proteína p53 após o dano ao DNA está associada com um aumento da apoptose. Assim, mutações neste gene, o insucesso no reparo dos danos ao DNA ou a falha no processo de morte celular programada perpetua e amplifica as mutações nas células epidérmicas o que pode levar ao processo de carcinogênese na pele (Zambetti e Levine, 1993; White, 1996; Claerhout et al., 2006).

Há fortes evidências de que a radiação UVB seja o principal fator de risco ambiental que proporciona o desenvolvimento de carcinoma basocelular e carcinoma celular escamoso (cânceres do tipo não melanoma). Já o desenvolvimento de melanoma cutâneo maligno é 
causado pela ação conjunta das radiações UVB e UVA e está diretamente relacionado à indução de danos oxidativos na pele provocado pelas Espécies Reativas de Oxigênio (EROs) (Wittgen e Van Kempen, 2007).

Para manifestar seus efeitos nas células, a radiação UV é absorvida por cromóforos celulares, como os aminoácidos aromáticos, principalmente triptofano e tirosina, proteínas, DNA, RNA, lipídios e melanina, que são capazes de absorver essa energia e convertê-la em energia química. Esses cromóforos energizados podem reagir com o oxigênio molecular resultando na geração das EROs. As EROs podem ser de dois tipos: radicais livres (radicais hidroxila, peroxila e alcoxila, o ânion superóxido) e aquelas que não são radicais livres, mas são moléculas de oxigênio reativas capazes de iniciar reações oxidativas e gerar espécies de radicais livres em organismos vivos (oxigênio singlete, peróxido de hidrogênio, peróxido nitrito, ácido hipocloroso) (Pinnell, 2003; Cadet, Sage e Douki, 2005; Xu e Fisher, 2005; Verschooten et al., 2006; Guaratini, Medeiros e Colepicolo, 2007; Shah e Rawal Mahajan, 2013).

As EROs interagem facilmente com as células do tecido humano e possuem grande potencial destrutivo. $\mathrm{O}$ oxigênio molecular $\left(\mathrm{O}_{2}\right)$ tem sua reatividade aumentada através da adição de um elétron ou por meio da transferência de energia, sendo por sua vez, convertido em oxigênio singlete $\left({ }^{1} \mathrm{O}_{2}\right)$ ou ânion superóxido $\left(\mathrm{O}_{2}{ }^{\circ}\right)$ (figura 3). $\mathrm{O} \mathrm{O}_{2}{ }^{\circ-}$ é extremamente instável e pode ser ainda convertido em peróxido de hidrogênio $\left(\mathrm{H}_{2} \mathrm{O}_{2}\right)$, espontaneamente ou enzimaticamente pela superóxido dismutase (SOD). Além disso, o $\mathrm{O}_{2}{ }^{-}$gera alguns produtos tóxicos e muito reativos, como o ácido hipocloroso e o peroxinitrito (Scandalios, 1993; Valko et al., 2007; Chen, Hu e Wang, 2012).

$\mathrm{O}_{2} \mathrm{O}_{2}$ é mais estável do que o $\mathrm{O}_{2}{ }^{\circ-}$ e pode permear através das membranas lipídicas celulares. Adicionalmente, $\mathrm{o} \mathrm{H}_{2} \mathrm{O}_{2}$ também pode ser convertido no radical hidroxila $(\bullet \mathrm{OH})$ na presença do íon ferro $\left(\mathrm{Fe}^{2+}\right)$ ou cobre $\left(\mathrm{Cu}^{2+}\right)$ através da reação de Fenton $\left(\mathrm{Fe}^{2+}+\mathrm{H}_{2} \mathrm{O}_{2} \rightarrow\right.$ $\mathrm{Fe}^{3+}+{ }^{\circ} \mathrm{OH}+1$ ín hidroxil) (Chen, Hu e Wang, 2012). Os íons metálicos de transição, ferro e

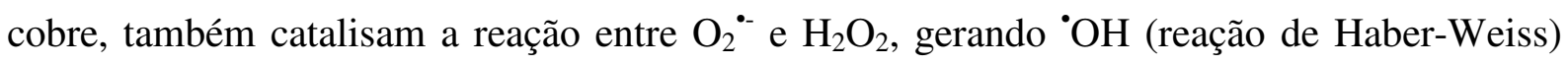
(Dizdaroglu e Jaruga, 2012).

$\mathrm{O} \mathrm{H}_{2} \mathrm{O}_{2}$ pode ser eliminado pela ação da glutationa peroxidase presente no citosol, na mitocôndria ou no meio extracelular, e sua ação é converter o $\mathrm{H}_{2} \mathrm{O}_{2}$ em $\mathrm{H}_{2} \mathrm{O}$ e os hidroperóxidos lipídicos oriundos das membranas em álcoois estáveis. Essa enzima catalisa a reação de oxidação da glutationa reduzida (GSH) para a sua forma oxidada (GSSG) através da doação de elétrons. A GSH poderá ser regenerada com o auxílio da glutationa redutase (GR), com transferência do hidrogênio da nicotinamida adenina nucleotídeo reduzido (NADPH). 
Outra via de neutralização do $\mathrm{H}_{2} \mathrm{O}_{2}$ seria sua conversão em ácido hipocloroso ( $\mathrm{HClO}$ ) pela enzima mieloperoxidase (MPO), uma heme peroxidase abundantemente encontrada nos lisossomos dos neutrófilos (Comhair e Erzurum, 2005; Day, 2009; Dickinson e Chang, 2011).

$\mathrm{O}$ radical ${ }^{\circ} \mathrm{OH}$ é uma das EROs mais instáveis que existe no sistema biológico, pois é capaz de reagir com diversas biomoléculas capazes de ceder elétrons, como DNA, enzimas, proteínas e aminoácidos. Esse radical também pode reagir com fosfolipídeos de membrana, promovendo a sua desorganização, formando radicais alcoxila $\left(\mathrm{LO}^{\circ}\right)$, radicais peroxila $\left(\mathrm{LOO}^{\circ}\right)$ e hidroperóxidos lipídicos (LOOH), precursores da peroxidação lipídica (Valko et al., 2007; Chen, $\mathrm{Hu}$ e Wang, 2012). Um resumo da reação em cadeia da geração de EROs está apresentado na figura 3.

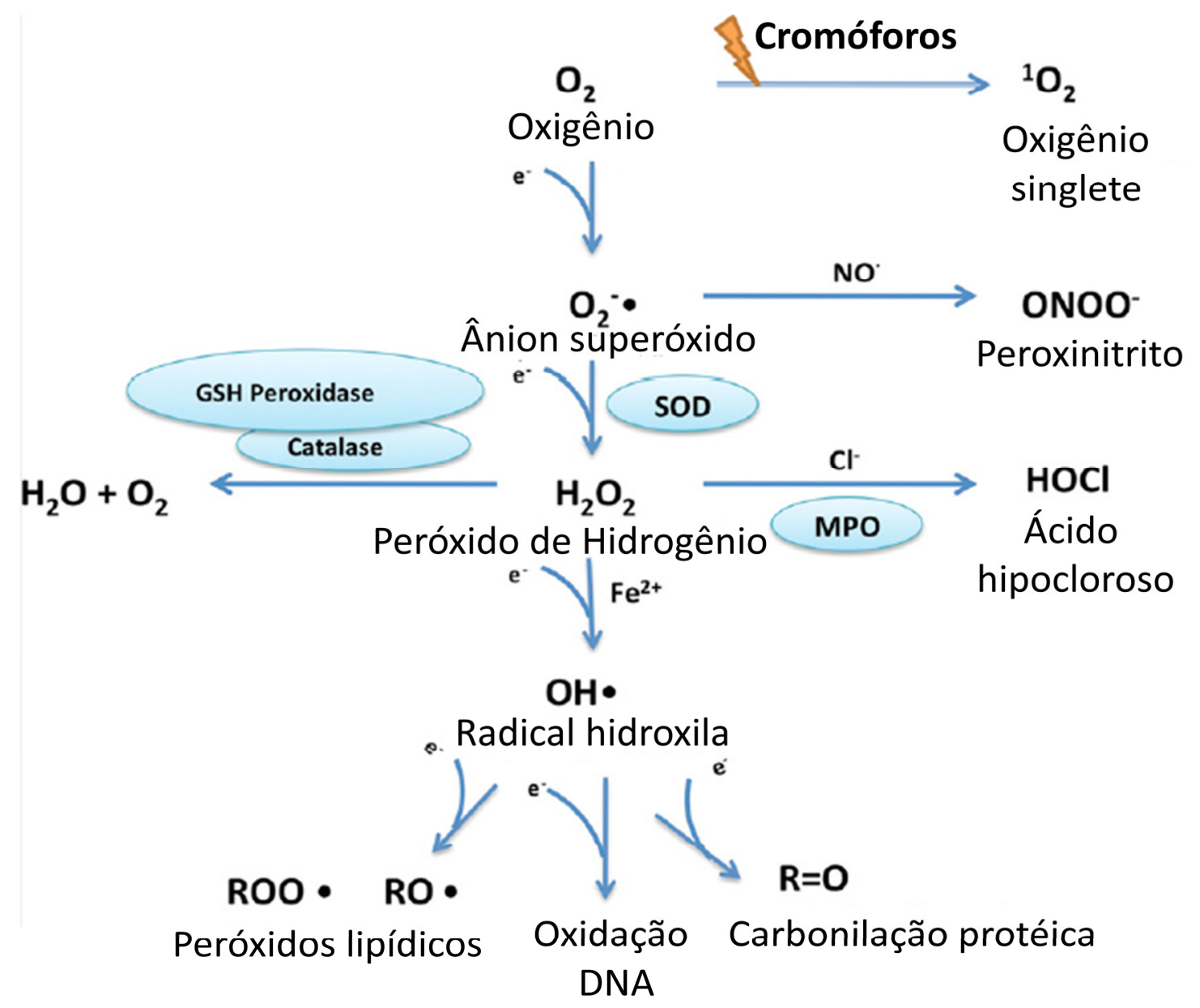

Figura 3: Reação em cadeia da geração de Espécies Reativas de Oxigênio. Adaptado por Chen, Hu e Wang (2012).

A superprodução de EROs sobrecarrega a capacidade de defesa do sistema antioxidante endógeno, levando ao estresse oxidativo e fotolesões em macromoléculas da pele, tais como proteínas e lipídeos. Sob circunstâncias que promovem o estresse oxidativo, a concentração de radicais livres aumenta incontrolavelmente, alterando a homeostasia cutânea 
(Sierens et al., 2001). Assim, ocorre uma série de efeitos prejudiciais às células da pele humana. A figura 4 mostra o esquema simplificado das alterações bioquímicas e vias de sinalização envolvidas na pele após exposição à radiação UV.

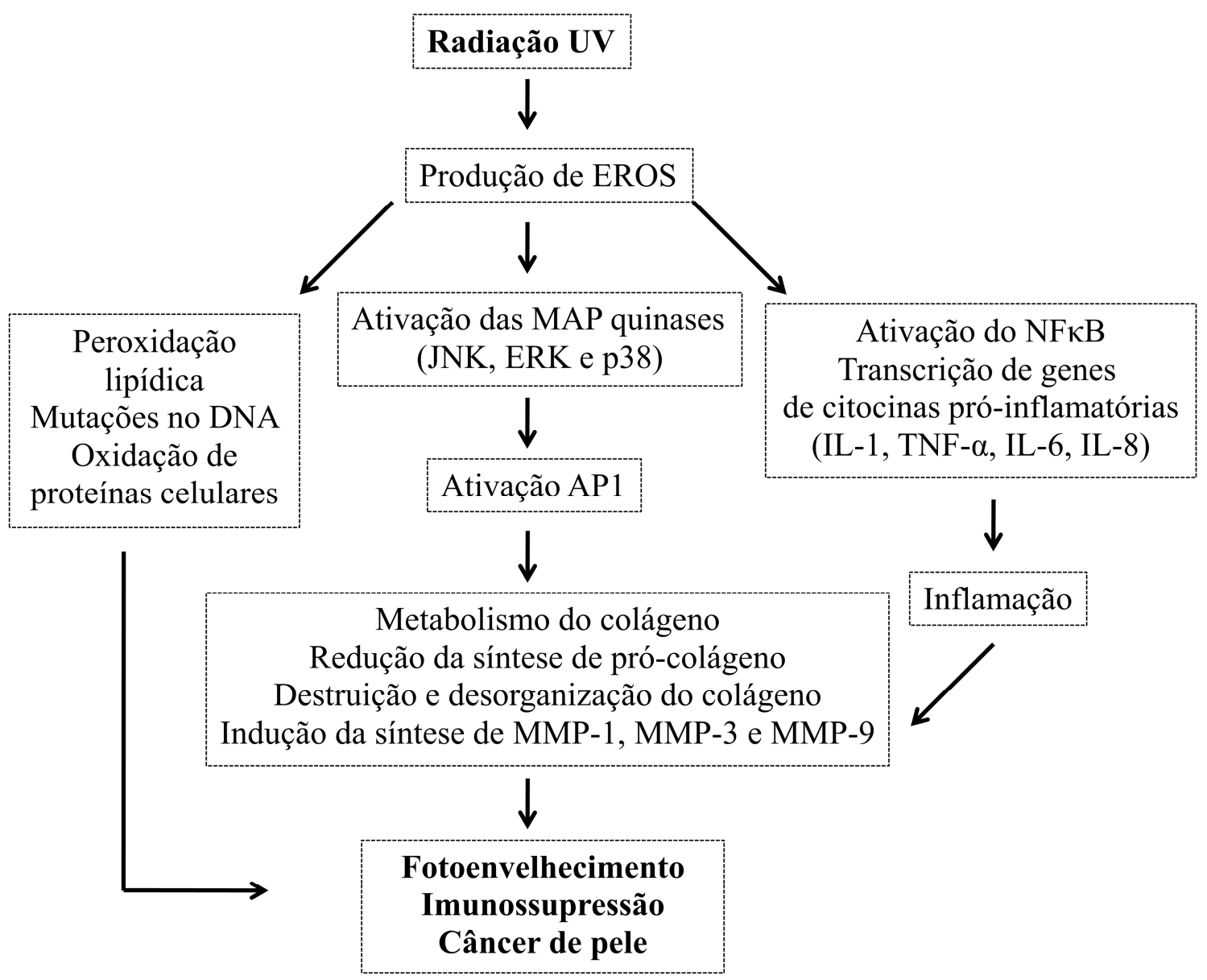

Figura 4: Esquema simplificado das alterações bioquímicas e vias de sinalização envolvidas na pele após exposição à radiação UV. Adaptado por Zouboulis e Makrantonaki (2011) e Chen, Hu e Wang (2012).

O excesso de EROs podem desencadear uma incontrolável reação em cadeia de peroxidação lipídica (LPO), um processo prejudicial conseqüente da exposição a radiação UV e que gera produtos pro-inflamatórios (Girotti et al., 2000). A peroxidação lipídica é o processo pelo qual as EROs reagem com ácidos graxos poliinsaturados dos fosfolipídios das membranas celulares, conduzindo a uma desorganização da membrana celular e liberação de fosfolipídios. Estes fosfolipídios quando associados ao aumento de atividade da fosfolipase $\mathrm{A}_{2}$ e da ciclooxigenase-2 (COX-2), superexpressas devido à radiação $\mathrm{UV}$, resultam em elevados níveis de produção de prostaglandinas $(\mathrm{PG})$, incluindo a prostaglandina $\mathrm{E}_{2}\left(\mathrm{PGE}_{2}\right)$, que induzem inflamação na pele. As alterações nas membranas desenvolvem transtornos na permeabilidade, alterando o fluxo iônico e o fluxo de outras substâncias, o que resulta na 
perda da seletividade para entrada e/ou saída de nutrientes e substâncias tóxicas à célula, além de promover alterações no DNA, oxidação da LDL (colesterol de baixa densidade) e comprometimento dos componentes da matriz extracelular (proteoglicanos, colágeno e elastina) (Halliday, 2005; Svobodova, Walterova e Vostalova, 2006; Zhou et al., 2012).

O processo inflamatório resultante da radiação UV sobre a pele induz alterações que incluem eritema, infiltrado de células inflamatórias como macrófagos e neutrófilos e alterações na produção de citocinas a partir de queratinócitos e melanócitos na epiderme e de fibroblastos, células endoteliais, mastócitos e outras células inflamatórias presentes na derme (Kondo, 2000; Coussens e Werb, 2001; Sander et al., 2004).

A liberação da citocina inflamatória interleucina (IL) -1 ocorre a partir do estrato córneo e por conseguinte iniciam-se as reações inflamatórias nas diferentes camadas da pele (Kupper e Groves, 1995; Wood et al., 1996). Além disso, a radiação UV estimula a síntese e liberação do fator de necrose tumoral- $\alpha(\mathrm{TNF}-\alpha)$ de queratinócitos para a corrente sanguínea, sugerindo que citocinas derivadas de células epidérmicas podem mediar reações inflamatórias sistêmicas. A ativação da síntese do TNF- $\alpha$ se dá parcialmente pela IL-1 e parcialmente pelas EROs. Estas duas citocinas "primárias" IL-1 e TNF- $\alpha$ auto-induzem sua produção pelos queratinócitos e estimulam a produção de outra citocinas pró-inflamatórias, tais como IL-6, IL-8, IL-10 e IL-12, que por sua vez elevam a produção de EROS e aumentam o estresse oxidativo, que se permanecer não reparado pode iniciar a fotocarcinogênese (Kock et al., 1990; Corsini et al., 1995; Pillai, Oresajo e Hayward, 2005; Thomas-Ahner et al., 2007; Poquet, Clifford e Williamson, 2008; Sivamani e Maibach, 2009).

As citocinas atuam principalmente através de duas vias: por estimulação dos níveis do fator nuclear - kappa B (NF-kB) no citoplasma (Adhami, Afaq e Ahmad, 2003; Tanaka et al., 2005; 2007) ou por estimulação dos níveis das proteínas quinases ativadas por mitógenos (MAP quinases) na célula (Mittelstadt et al., 2005).

O NF-kB é um complexo de proteínas que controla a transcrição do DNA, que normalmente é retido no citoplasma como um complexo inativo ligado a uma molécula inibidora, denominada IkB. Com a exposição da pele aos raios UV, há a secreção de mediadores inflamatórios como IL-1 e TNF- $\alpha$, os quais atuam como estimuladores e promovem a degradação do complexo NF-kB/IkB. Então o NF-kB é translocado para o núcleo, acarretando a ativação de genes envolvidos na produção de substâncias próinflamatórias (IL-1, IL-6 e TNF- $\alpha$ ) e levando à formação de metaloproteinases (Bond, Baker e Newby, 1999; Sun, Malacinski e Yokota, 2002; Chung, 2003; Shah e Rawal Mahajan, 2013). 
As MAP quinases são mediadores na transdução do sinal da superfície celular para o núcleo e são de grande importância no processo de ativação e controle da expressão gênica (Fisher et al., 1998). A família das MAP quinases é composta por três membros: proteínas quinases ativadas por estresse (quinase c- Jun N-terminal (JNK) e quinase p38) e a proteína quinase regulada por sinais extracelulares (ERK). A ERK é ativada em resposta a fatores de crescimento e estimula a proliferação, sobrevivência e diferenciação celular tendo papel importante também na promoção de tumores, principalmente estimulados pelo estado oxidativo (Kallunki et al., 1994). A JNK e p38 são principalmente ativadas por estressores ambientais como a exposição RUV, citocinas inflamatórias, choque térmico e agentes causadores de danos de DNA. A fosforilação destas proteínas tem papel importante na diferenciação celular e resposta inflamatória. O balanço dinâmico na ativação das diversas vias das MAP quinases é importante para sobrevivência celular, de modo que estas atuam nas células controlando a resposta aos diversos sinais do meio (Chung, 2003; Melnikova e Ananthaswamy, 2005; Mantena e Katiyar, 2006).

A ativação da família das MAP quinases resulta no aumento da expressão do fator de transcrição c-Jun na pele humana, que juntamente com o fator de transcrição constitutivamente expresso, c-Fos, formam o complexo AP-1, um fator de transcrição altamente ativo. A atividade aumentada de AP-1 é necessária para a indução de membros chave da família das metaloproteinases (MMPs), as quais são responsáveis pela degradação de colágeno e fibras elásticas na pele (Kim, Lee, et al., 2005; Xu e Fisher, 2005).

A radiação UV induz aumento da atividade enzimática de pelo menos três MMPs. São elas: MMP-1, que degrada fibras de colágeno tipo I e III; MMP-3 (estromelisina-1) que degrada colágeno tipo IV; e MMP-9 (gelatinase-B) que degrada fragmentos de colágeno gerados por MMP-1. Juntas, estas MMPs têm a capacidade de degradar a maior parte das proteínas estruturais que compõe o tecido conjuntivo dérmico (Fisher et al., 2001; Xu e Fisher, 2005).

Os fibroblastos estão presentes na derme e são responsáveis principalmente pela produção de fibras de colágeno tipo I e III, as quais fornecem força e resistência à pele. $\mathrm{O}$ colágeno tipo I é o mais abundante na pele, produzido a partir do pró-colágeno tipo I. Um dos principais danos causados pela exposição à radiação UVB é a degradação das fibras elásticas, do colágeno e das glicosaminoglicanas da matriz extracelular da derme, o que acarreta a perda de elasticidade e contribui para a formação de rugas e fotoenvelhecimento da pele (Shah e Rawal Mahajan, 2013). 


\subsection{Compostos fenólicos extraídos das folhas de Byrsonima crassifolia e a (+) catequina como agentes fotoquimioprotetores}

Para limitar os danos induzidos pela radiação UV é recomendado o uso de protetor solar com um fator de proteção solar igual ou superior a 15 . No entanto, o aumento do uso de protetores solar tem coincidido com o aumento do câncer de pele, estudos conduzidos por Hanson, Gratton e Bardeen (2006) mostram que quando os filtros solares benzofenona, octilmetoxicinamato e salicilato de octila penetram na epiderme viável da pele, o nível de EROs aumenta além daquele produzido naturalmente pelos cromóforos epiteliais sob irradiação.

Assim, a fotoquimioproteção tem sido apreciada como uma maneira viável em reduzir a ocorrência de uma variedade de desordens de pele. A ação dos agentes fotoquimioprotetores pode ser alcançada tanto pela prevenção, quanto pela correção dos danos que a radiação UV (principalmente UVB) causa na pele, devido a diversos fatores como resumidos na figura 5 (F'guyer, Afaq e Mukhtar, 2003; Afaq, Adhami e Mukhtar, 2005).

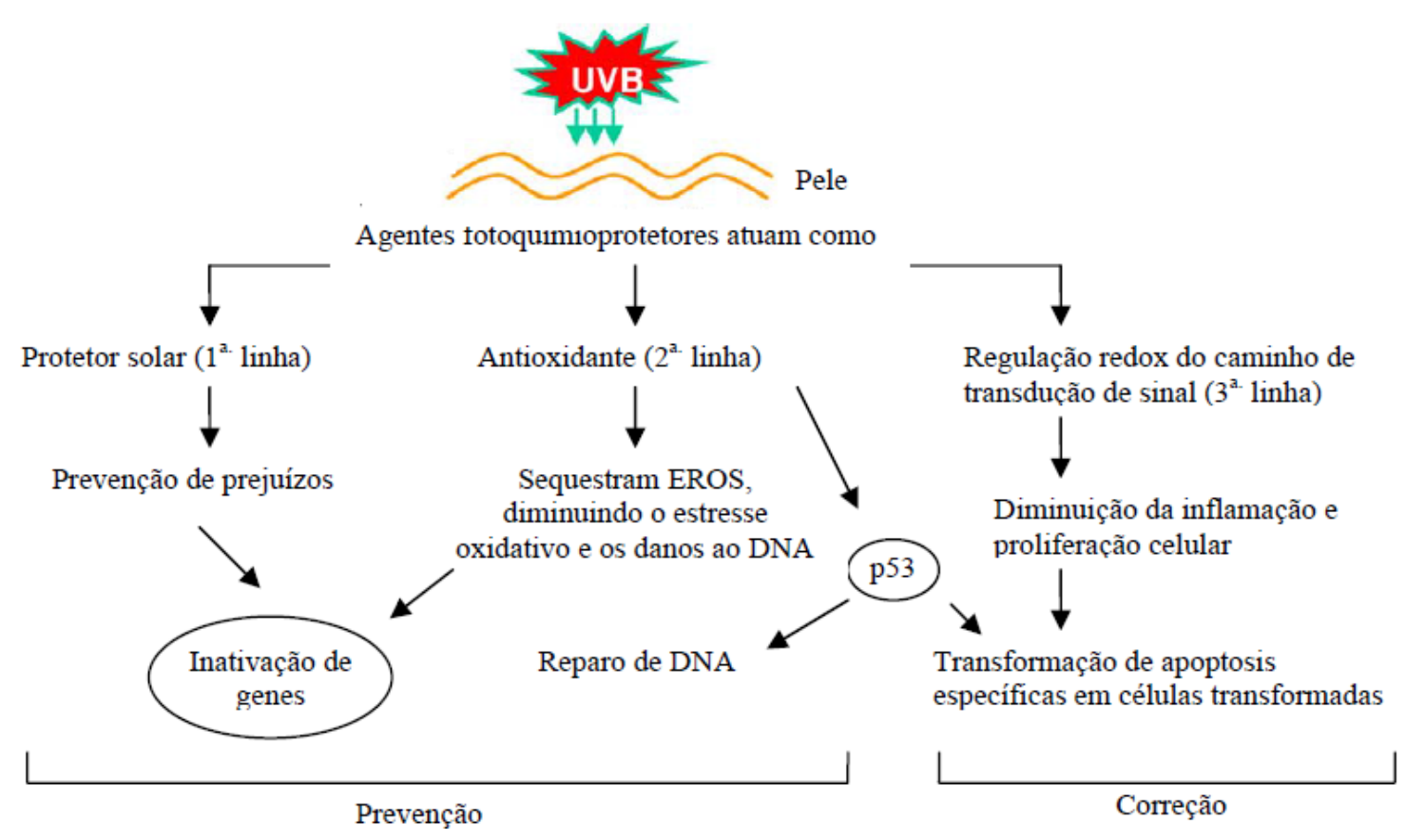

Figura 5: Ação dos agentes fotoquimioprotetores na pele. Adaptado por Afaq, Adhami e Mukhtar (2005).

Os compostos antioxidantes são considerados substâncias que retardam ou previnem significativamente a oxidação de lipídios ou outras moléculas por inibirem a iniciação ou a propagação da reação de oxidação em cadeia ocasionada pelas EROs (Al-Mamary, Al-Meeri 
e Al-Habori, 2002; Moreira et al., 2002; Chanwitheesuk, Teerawutgulrag e Rakariyatham, 2005; Wu et al., 2005; Lima et al., 2006). Uma ampla variedade de estudos tem mostrado que compostos antioxidantes naturais como o licopeno, carotenóides, catequinas do chá verde (epigalocatequina galato), vitamina E, vitamina A e quercetina poderiam ser usados em produtos tópicos para o tratamento ou prevenção dos efeitos causados pela radiação UV (Casagrande et al., 2006; Wright, Spencer e Flowers, 2006; Di Mambro e Fonseca, 2007; Filip et al., 2011).

Há, portanto, um crescente interesse pelo uso oral ou tópico de antioxidantes provenientes de fontes naturais, com propriedades anti-inflamatórias, anticarcinogênicas e imunomodulatórias para prevenção dos danos induzidos pela radiação UV, incluindo câncer de pele (Baliga e Katiyar, 2006). Assim, a aplicação tópica desses agentes, sozinhos ou em formulações, representa uma estratégia interessante de proteção cutânea contra o estresse oxidativo ocasionado pela radiação UV (Guaratini, Medeiros e Colepicolo, 2007).

Sendo assim, a (+) catequina (CAT) e o extrato ou a fração de folhas de Byrsonima crassifolia (BC) podem ser considerados fortes candidatos a serem veiculados em formulações tópicas fotoquimioprotetoras para prevenção e/ou tratamento dos danos causados pela radiação UV à pele. Os efeitos benéficos do extrato e da fração de $\mathrm{BC}$ podem ser relacionados ao elevado conteúdo de compostos fenólicos e a CAT quanto à capacidade de sequestro de radicais livres (Morel et al., 1993; Lotito e Fraga, 1998; Nakao, Takio e Ono, 1998; Silva et al., 2007; Souza et al., 2008).

A árvore da Byrsonima crassifolia (L) H.B.K (murucizeiro) é uma espécie tropical da família das Malpighiaceae amplamente distribuída na América Central e do Sul. As folhas e cascas são utilizadas medicinalmente pelos povos nativos para tratar tosses, problemas gastrointestinais, infecções cutâneas e mordidas de cobras (Bejar e Malone, 1993; Bejar et al., 1995; MartíNez-Vázquez et al., 1999) (Figura 6). 

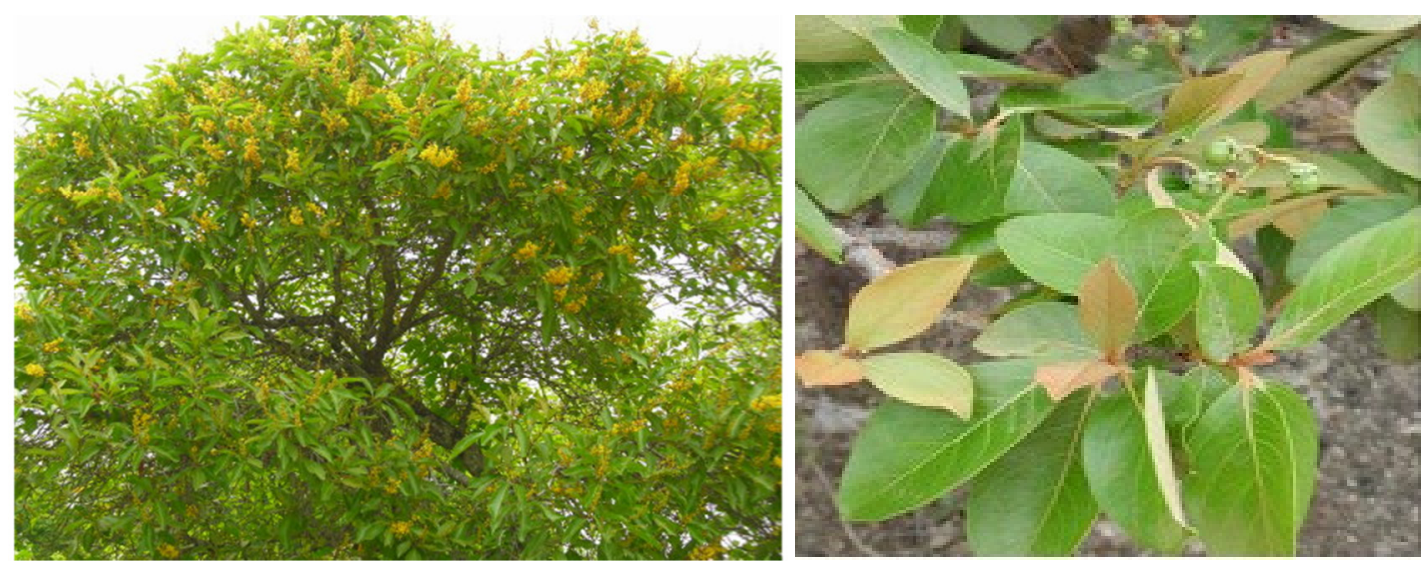

Figura 6: Árvore e folhas de Byrsonima crassifolia. Reproduzido de http://www.acguanacaste.ac.cr/loras_acg/aratinga.html e http://herbario.unellez.edu. ve/>. Acesso em: janeiro de 2015.

Estudos experimentais com folhas e casca desta espécie demonstraram efeito espasmogênico (Bejar et al., 1995), atividade antiprotozoários (Peraza-Sanchez et al., 2007) e antiinflamatória (Maldini et al., 2009). Estudos realizados por Silva et al., (2007) relatam significante capacidade antioxidante do extrato hidroalcoólico de BC, provavelmente devido à presença de compostos fenólicos, entre eles estão: ácido gálico, (+) catequina; (-) epicatequina; epigalocatequina; epigalocatequina-3-galato, quercetina-3-O-L- $\alpha$-Larabinopiranosídeo, quercetina-3-galactosídeo, quercetina-3-O-[6-galoil]galactosídeo, entre outros (Bejar e Malone, 1993; Bejar et al.,1995; Souza, 2007). Dentre os compostos identificados em extratos das folhas de $\mathrm{BC}$, um dos majoritários é a (+) catequina (CAT). Assim, por este motivo, e devido à ausência de estudos deste polifenol contra os danos induzidos pela radiação UV e pelo baixo custo, a CAT foi escolhida como padrão de estudo no presente trabalho.

A CAT (figura 7) é um flavonóide da classe dos flavanóis e está presente nos chás, em sementes de frutas tais como maçã e uva, no vinho tinto e no chocolate. A CAT é um potente antioxidante que elimina de forma eficiente uma variedade de radicais livres. Estudos mostram que a CAT quela metais de transição e inibe a peroxidação lipídica. No entanto, apesar da CAT ser barata e abundante em inúmeras fontes vegetais, pouca atenção tem sido dada para avaliação da sua atividade biológica em sistemas in vitro e in vivo (Morel et al., 1993; Lotito e Fraga, 1998; Nakao, Takio e Ono, 1998; Arts, Hollman e Kromhout, 1999; Jeon et al., 2003; Wu et al., 2006). 


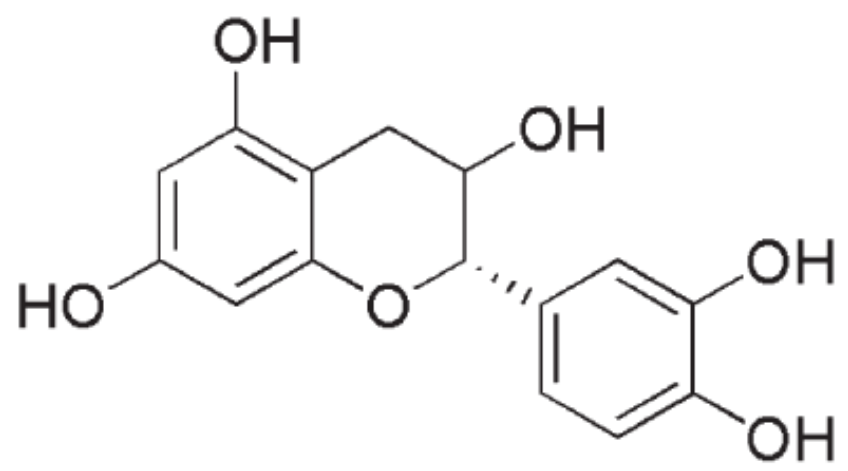

Figura 7: Estrutura química da (+) catequina.

\subsection{Estudo de penetração cutânea}

A pele está envolvida em numerosos processos físicos e bioquímicos, sendo o mais importante deles a função protetora, prevenindo tanto a passagem de substâncias exógenas estranhas como a perda de líquidos do corpo (Elias, 2005; Herrling, Jung e Fuchs, 2006; Rubio et al., 2011). Para que o princípio ativo apresente potencial fotoquimioprotetor contra os danos oxidativos induzidos pela radiação UV na pele, é necessário que este seja liberado da formulação na qual foi incorporado e alcance as camadas da pele onde são geradas as EROs, modulando a função barreira da pele (Vicentini et al., 2009). Mas o que representa uma proteção ao ser humano se torna um fator limitante na ação das substâncias de atividade antioxidante e terapêutica aplicadas topicamente (Hadgraft, 2004).

A penetração de substâncias ativas na pele depende de dois passos consecutivos: a liberação desta substância pela formulação e, sua subseqüente penetração cutânea. A penetração de substâncias através da pele, em condições normais pode ocorrer por três rotas possíveis (Figura 8). O primeiro e o segundo são através das rotas inter e transcelulares e o terceiro é via apêndices, folículos pilosos e ductos de glândulas (Potts e Guy, 1992; Abraham, Chadha e Mitchell, 1995). O caminho intercelular envolve a passagem somente pelos domínios lipídicos intercelulares, já o caminho transcelular, o princípio ativo atravessa as células e os espaços intercelulares (Illel, 1997; Moser et al., 2001). 

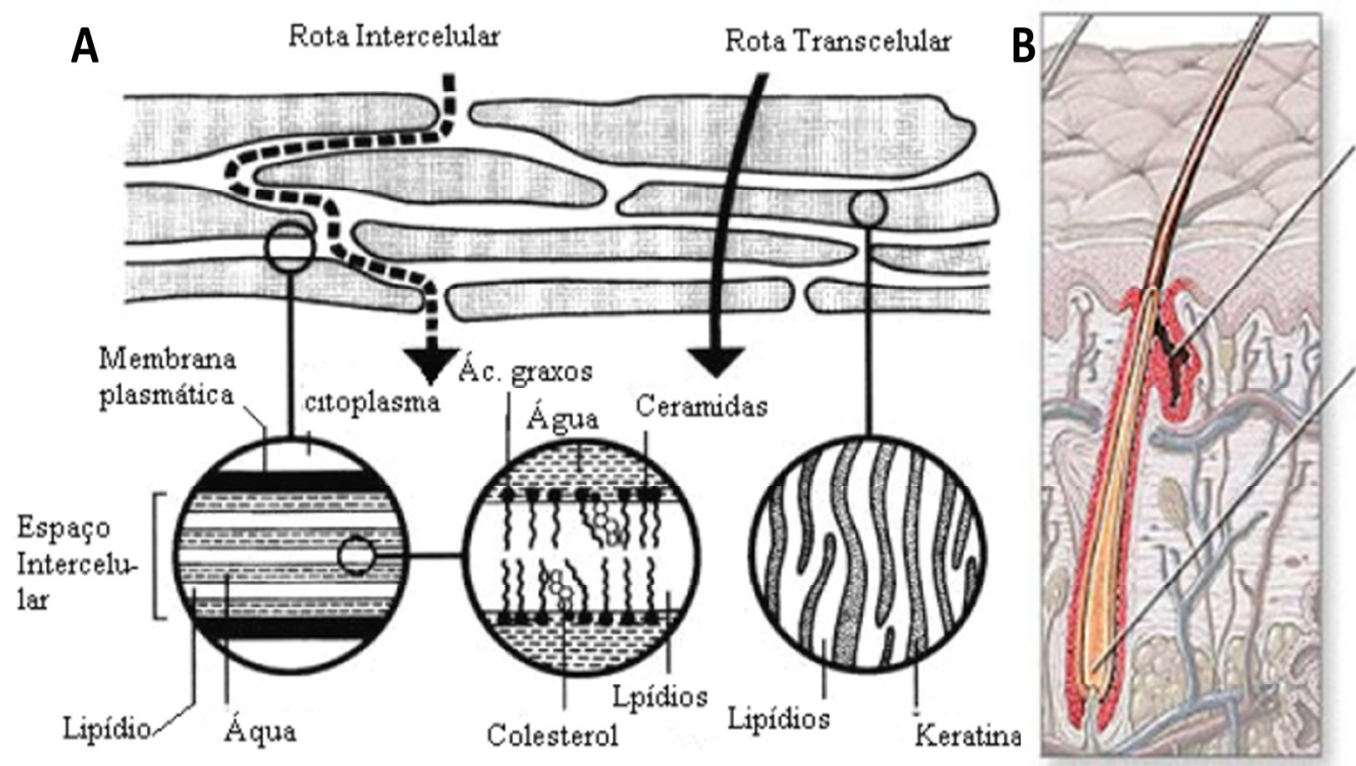

Glándula sebácea

Folículo

piloso

Figura 8: Mecanismos de penetração de ativos pelo estrato córneo. (A) através da matriz lipídica, entre os corneócitos (penetração intercelular) e através dos corneócitos e da matriz lipídica (penetração transcelular), Reproduzido de Moser et al. (2001) e (B) através dos apêndices cutâneos, reproduzido de: $<\mathrm{http}: / /$ draangelicapimenta.blogspot.co m.br/2010_11_01_archive.html>. Acesso em: Janeiro de 2015.

A penetração de substâncias através da pele, em condições normais, ocorre principalmente através dos espaços intercelulares (Hadgraft, 2004). O espaço intercelular possui lipídios estruturados e a molécula em difusão tem que passar por uma variedade de domínios lipofílicos e hidrofílicos antes de atingir a junção entre o estrato córneo e a epiderme viável (Abraham, Chadha e Mitchell, 1995; Hadgraft, 2004).

No que diz respeito às propriedades de absorção e penetração cutânea das substâncias na pele, metodologias in vitro e in vivo são adequadas. Normalmente são realizados estudos utilizando pele de camundongo, pele humana proveniente de cirurgia ou pele de orelha de porco, que é considerado o melhor modelo de pele, pois além de possuir maior disponibilidade, possui propriedades histológicas e fisiológicas similares a da pele humana (Pagliara et al., 1999).

A capacidade de uma molécula penetrar o estrato córneo depende de muitos parâmetros físicos-químicos, tais como peso molecular, lipofilicidade, polaridade, capacidade para formar ligações de hidrogênio, solubilidade, e para ácidos ou bases, o valor de pKa (Potts, 1997). De acordo com a primeira Lei de Fick, o fluxo máximo de penetração através da pele, o qual pode ser alcançado após a aplicação de um veículo saturado, é basicamente determinado por quatro fatores: a difusão no estrato córneo, a espessura do estrato córneo, a 
lipofilicidade da substância em termos de coeficiente de partição entre a pele e o veículo e a solubilidade do princípio ativo no veículo (Varvaresou, 2006).

Para determinar as quantidades de substâncias capazes de penetrar na pele é utilizado o método de difusão em células de Franz, que é constituído por dois compartimentos separados por um disco de pele humana ou de porco. O compartimento inferior é constituído de um fluido receptor que simula a circulação sanguínea. A substância teste é colocada sobre o disco de pele e a quantidade retida é medida pela análise das camadas da pele trituradas (Varvaresou, 2006).

Para realização dos estudos de penetração cutânea de uma formulação, a(s) substância(s) ativa(s) é/são quantificada(s) por metodologia analítica. Normalmente a quantidade de substância ativa detectada é muito pequena e desta forma somente métodos analíticos muito sensíveis como Cromatografia Líquida de Alta Eficiência (CLAE) são utilizados. Sabe-se que extratos vegetais são amostras complexas formadas por vários constituintes, então a atividade esperada pode ser devido à ação sinérgica de vários compostos que estão presentes no extrato ou fração. Assim, uma alternativa para poder avaliar a real atividade desempenhada pelo extrato seria determinar a atividade antioxidante na pele triturada e extraída após o estudo de penetração cutânea. Desta forma, a determinação da atividade antioxidante é uma alternativa que representa de forma adequada a penetração cutânea do extrato ou da fração de BC incorporados em formulações tópicas fotoquimioprotetoras.

Além de penetrar na epiderme/derme, agentes fotoquimioprotetores devem ser fotoestáveis, uma vez que a degradação de compostos induzida pela luz pode resultar em uma diminuição da eficiência e também em efeito adverso após a administração pela geração de metabólitos indesejáveis (Vicentini et al., 2007). Estes metabólitos podem causar reações alérgicas, uma vez que eles podem interagir com adjuvantes da formulação ou componentes da pele, como o sebo, podendo levar à formação de moléculas com propriedades tóxicas (Gaspar e Maia Campos, 2006).

Assim, em colaboração com a empresa Amazon Dreams S.A. (localizada em Belém do Pará e incubada na UFPA), que gentilmente cedeu o extrato e a fração de média polaridade de Byrsonima crassifolia, este trabalho avaliou o potencial fotoquimioprotetor in vitro e in vivo da fração de BC e da CAT, com o objetivo de preparar formulações adicionadas destes ativos, que sejam estáveis física e quimicamente e que promovam uma maior penetração de compostos antioxidantes na pele. É importante ressaltar que extrato e/ou fração de $\mathrm{BC}$ nunca haviam sido incorporados em formulações tópicas, nem tão pouco 
haviam estudos direcionados para avaliar o potencial fotoquimioprotetor, o que ressalta a importância científica do trabalho realizado. 
5 Conclusões 
Diante do exposto, o presente estudo mostra que a fração de $\mathrm{BC}$, bem como o padrão CAT possuem um papel importante na proteção contra danos diretos e/ou oxidativos causados à cultura de queratinócitos e à pele dos camundongos sem pelos por sua exposição à radiação UVB, o que faz destes ativos agentes promissores para uso em estratégias de fotoquimioproteção e consequente prevenção/tratamento dos danos induzidos pela radiação UVB à pele.

Assim, foi observado que a fração de BC atua modulando várias vias de sinalização induzida pela radiação UVB por diversos mecanismos: inibição da peroxidação lipídica, proteção do sistema antioxidante endógeno por manutenção dos níveis da glutationa reduzida, ação antiiflamatória por inibição das metaloproteinases de matriz (MMP-9), do infiltrado inflamatório na pele e das citocinas IL-1 $\beta$ e IL-6, assim como a CAT, que não foi eficiente apenas contra a inibição da MMP-9.

Deve-se destacar ainda que o efeito fotoquimioprotetor in vitro apresentado pela CAT foi numa concentração cerca de 2 à 4 vezes maior do que aquela utilizada para fração de $\mathrm{BC}$, mostrando que o enriquecimento da fração de $\mathrm{BC}$ em compostos fenólicos de média polaridade foi vantajoso, visto que a mistura de compostos polifenólicos pode agir de forma mais eficiente do que o composto isolado, por mecanismos de ações complementares evitando danos causados por um estimulo específico (radiação UVB) pela alta atividade antioxidante (fortalecimento do sistema imune ou ativar um sistema de proteção enzimática endógena), garantindo a homeostasia do organismo.

Portanto, a formulação tipo gel adicionada da fração de BC enriquecida de compostos fenólicos (AG, CAT, EC, EGCG e QG) foi eficiente em promover a penetração de compostos antioxidantes na pele de orelha de porco e na pele de camundongos sem pelos, e assim fornecer o efeito fotoquimioprotetor desejado, contribuindo significativamente para o futuro desenvolvimento e aplicabilidade da fração de $\mathrm{BC}$ ou de outros extratos vegetais ricos em polifenóis como ativos fotoquimioprotetores. Sendo assim, mais estudos relacionados à eficácia da fração de $\mathrm{BC}$ merecem ser realizados para o completo entendimento do seu efeito na prevenção e/ou tratamento de doenças da pele causada pela radiação UVB. 
Referências 98

6 Referências 
ABLA, M. J.; BANGA, A. K. Quantification of skin penetration of antioxidants of varying lipophilicity. International Journal of Cosmetic Science, v. 35, n. 1, p. 19-26, 2013.

ABRAHAM, M. H.; CHADHA, H. S.; MITCHELL, R. C. The Factors that Influence Skin Penetration of Solutes*. Journal of Pharmacy and Pharmacology, v. 47, n. 1, p. 8-16, 1995.

ABU ZAID, M. et al. Inhibition of UVB-mediated oxidative stress and markers of photoaging in immortalized HaCaT keratinocytes by pomegranate polyphenol extract POMx. Photochemistry and Photobiology, v. 83, n. 4, p. 882-888, Jul-Aug 2007.

ADHAMI, V. M.; AFAQ, F.; AHMAD, N. Suppression of ultraviolet B exposure-mediated activation of NF-kappaB in normal human keratinocytes by resveratrol. Neoplasia, v. 5, n. 1, p. 74-82, Jan-Feb 2003.

ADHAMI, V. M. et al. Phytochemicals for prevention of solar ultraviolet radiation-induced damages. Photochem Photobiol, v. 84, n. 2, p. 489-500, Mar-Apr 2008.

AFAQ, F. et al. Inhibition of ultraviolet B-mediated activation of nuclear factor kappaB in normal human epidermal keratinocytes by green tea Constituent (-)-epigallocatechin-3gallate. Oncogene, v. 22, n. 7, p. 1035-44, Feb 202003.

AFAQ, F.; ADHAMI, V. M.; MUKHTAR, H. Photochemoprevention of ultraviolet B signaling and photocarcinogenesis. Mutat Res, v. 571, n. 1-2, p. 153-73, Apr 2005.

AFAQ, F.; MUKHTAR, H. Effects of solar radiation on cutaneous detoxification pathways. J Photochem Photobiol B, v. 63, n. 1-3, p. 61-9, Oct 2001.

AJAZUDDIN et al. Recent expansions in an emergent novel drug delivery technology: Emulgel. Journal of Controlled Release, v. 171, n. 2, p. 122-132, 10/28/ 2013.

AL-MAMARY, M.; AL-MEERI, A.; AL-HABORI, M. Antioxidant activities and total phenolics of different types of honey. Nutrition research (New York, N.Y.), v. 22, n. 9, p. 1041-1047, 2002.

ALONSO, C. et al. Antioxidative effects and percutaneous absorption of five polyphenols. Free Radic Biol Med, v. 75, p. 149-55, Oct 2014.

ANGERHOFER, C. K.; MAES, D.; GIACOMONI, P. U. Chapter 10 - The Use of Natural Compounds and Botanicals in the Development of Anti-Aging Skin Care Products. In: BY, E. e DAYAN, N. (Ed.). Skin Aging Handbook. Norwich, NY: William Andrew Publishing, 2009. p.205-263.

ARTS, I. C. W.; HOLLMAN, P. C. H.; KROMHOUT, D. Chocolate as a source of tea flavonoids. The Lancet, v. 354, n. 9177, p. 488, 8/7/ 1999.

ATOUI, A. K. et al. Tea and herbal infusions: Their antioxidant activity and phenolic profile. Food Chemistry, v. 89, n. 1, p. 27-36, 1// 2005.

BACKVALL, H. et al. Similar UV responses are seen in a skin organ culture as in human skin in vivo. Exp Dermatol, v. 11, n. 4, p. 349-56, Aug 2002. 
BALIGA, M. S.; KATIYAR, S. K. Chemoprevention of photocarcinogenesis by selected dietary botanicals. Photochem Photobiol Sci, v. 5, n. 2, p. 243-53, Feb 2006.

BARCHOWSKY, A.; FRLETA, D.; VINCENTI, M. P. Cytokine, v. 12, n. 10, p. 1469-79, Oct 2000.

BEJAR, E. et al. Constituents of Byrsonima crassifolia and their spasmogenic activity. International Journal of Pharmacognosy, v. 33, n. 1, p. 25-32, 1995.

BEJAR, E.; MALONE, M. H. Pharmacological and chemical screening of Byrsonima crassifolia, a medicinal tree from Mexico. Part I. J Ethnopharmacol, v. 39, n. 2, p. 141-58, Jun 1993.

BLOIS, M. S. Antioxidant Determinations by the Use of a Stable Free Radical. Nature, v. 181, n. 4617, p. 1199-1200, 04/26/print 1958.

BOND, M.; BAKER, A. H.; NEWBY, A. C. Nuclear Factor $\kappa$ B Activity Is Essential for Matrix Metalloproteinase-1 and -3 Upregulation in Rabbit Dermal Fibroblasts. Biochemical and Biophysical Research Communications, v. 264, n. 2, p. 561-567, 10/22/ 1999.

BORENFREUND, E.; PUERNER, J. A. Toxicity determined in vitro by morphological alterations and neutral red absorption. Toxicology Letters, v. 24, n. 2-3, p. 119-124, 2// 1985.

BRADFORD, M. M. A rapid and sensitive method for the quantitation of microgram quantities of protein utilizing the principle of protein-dye binding. Analytical Biochemistry, v. 72, n. 1-2, p. 248-254, 5/7/ 1976.

BRADLEY, P. P. et al. Measurement of cutaneous inflammation: estimation of neutrophil content with an enzyme marker. J Invest Dermatol, v. 78, n. 3, p. 206-9, Mar 1982.

BRASIL. Agência Nacional de Vigilância Sanitária - ANVISA. Guia para validação de métodos analíticos e bioanalíticos. $R E n^{\circ} 899$, de 29 de maio de 2003. Disponível em: $<$ http://www.anvisa.gov.br.>. Site visitado em: 15 de março, 2013.

BRASIL. Agência Nacional de Vigilância Sanitária - ANVISA. Gerência Geral de cosméticos. Guia de estabilidade de produtos cosméticos. Série qualidade 1. Brasília, 2004. Disponível em: <http://anvisa.gov.br/cosmeticos/guia_series.htm>. Acesso em 02 de maio de 2012.

BRIGANTI, S.; PICARDO, M. Antioxidant activity, lipid peroxidation and skin diseases. What's new. J Eur Acad Dermatol Venereol, v. 17, n. 6, p. 663-9, Nov 2003.

BRIGELIUS-FLOHÉ, R. Tissue-specific functions of individual glutathione peroxidases. Free Radical Biology and Medicine, v. 27, n. 9-10, p. 951-965, 11// 1999.

BROHEM, C. A. et al. Artificial skin in perspective: concepts and applications. Pigment Cell Melanoma Res, v. 24, n. 1, p. 35-50, Feb 2011.

BRONAUGH, R.L.; HOOD, H.L.; KRAELING, M.E.K.; YOURICK, J.J. Determination of percutaneous absorption by in vitro techniques. In: BRONAUGH, R.L., MAIBACH, H.I. Percutaneous absorption - Drugs, Cosmetics, Mechanisms and Methodology, $3^{\circ}$ ed., Marcel Dekker, New York, p. 229-234, 1999.

BUEGE, J. A.; AUST, S. D. Microsomal lipid peroxidation. Methods Enzymol, v. 52, p. 302-10, 1978. 
BURDA, S.; OLESZEK, W. Antioxidant and Antiradical Activities of Flavonoids. Journal of Agricultural and Food Chemistry, v. 49, n. 6, p. 2774-2779, 2001/06/01 2001.

BURGER, D. et al. Is IL-1 a good therapeutic target in the treatment of arthritis? Best Practice \& Research Clinical Rheumatology, v. 20, n. 5, p. 879-896, 10// 2006.

CADET, J.; SAGE, E.; DOUKI, T. Ultraviolet radiation-mediated damage to cellular DNA. Mutation Research-Fundamental and Molecular Mechanisms of Mutagenesis, v. 571, n. 1-2, p. 3-17, Apr 12005.

CAMPANINI, M. Z. et al. Efficacy of topical formulations containing Pimenta pseudocaryophyllus extract against UVB-induced oxidative stress and inflammation in hairless mice. J Photochem Photobiol B, v. 127, p. 153-60, Oct 52013.

CARINI, M. et al. Fluorescent probes as markers of oxidative stress in keratinocyte cell lines following UVB exposure. Farmaco, v. 55, n. 8, p. 526-34, Aug 2000.

CASAGRANDE, R. et al. In vitro evaluation of quercetin cutaneous absorption from topical formulations and its functional stability by antioxidant activity. International Journal of Pharmaceutics, v. 328, n. 2, p. 183-190, 1/10/ 2007.

CASAGRANDE R, GEORGETTI SR, VERRI WA JR, DORTA DJ, DOS SANTOS AC, FONSECA MJ. Protective effect of topical formulations containing quercetin against UVB-induced oxidative stress in hairless mice. J Photochem Photobiol B, v. 84, n. 1, p. 21 7, Jul 32006.

CASAGRANDE, R. Desenvolvimento de formulações tópicas contendo quercetina: controle físico-químico e avaliação da eficácia in vivo. Tese de doutorado - Faculdade de ciências farmacêuticas de Ribeirão Preto, Universidade de São Paulo, Ribeirão Preto, 2005.

CHANDRA JAGETIA, G. et al. Alteration in the glutathione, glutathione peroxidase, superoxide dismutase and lipid peroxidation by ascorbic acid in the skin of mice exposed to fractionated $\gamma$ radiation. Clinica Chimica Acta, v. 332, n. 1-2, p. 111-121, 6. 2003.

CHANWITHEESUK, A.; TEERAWUTGULRAG, A.; RAKARIYATHAM, N. Screening of antioxidant activity and antioxidant compounds of some edible plants of Thailand. Food Chemistry, v. 92, n. 3, p. 491-497, Sep 2005.

CHEN, L.; HU, J. Y.; WANG, S. Q. The role of antioxidants in photoprotection: a critical review. J Am Acad Dermatol, v. 67, n. 5, p. 1013-24, Nov 2012.

CHIANG, H.-M. et al. Michelia alba extract attenuates UVB-induced expression of matrix metalloproteinases via MAP kinase pathway in human dermal fibroblasts. Food and Chemical Toxicology, v. 50, n. 12, p. 4260-4269, 12// 2012.

CHO, H. S. et al. Anti-wrinkling effects of the mixture of vitamin C, vitamin E, pycnogenol and evening primrose oil, and molecular mechanisms on hairless mouse skin caused by chronic ultraviolet B irradiation. Photodermatol Photoimmunol Photomed, v. 23, n. 5, p. 155-62, Oct 2007.

CHOI, H. K. et al. Labisia pumila extract protects skin cells from photoaging caused by UVB irradiation. In: (Ed.). J Biosci Bioeng. Japan: 2009. Published by Elsevier B.V., v.109, 2010. p.291-6. 
CHUNG, J. H. Photoaging in Asians. Photodermatology Photoimmunology \& Photomedicine, v. 19, n. 3, p. 109-121, Jun 2003.

CLAERHOUT, S. et al. Pathways involved in sunburn cell formation: deregulation in skin cancer. Photochem Photobiol Sci, v. 5, n. 2, p. 199-207, Feb 2006.

COMHAIR, S. A.; ERZURUM, S. C. The regulation and role of extracellular glutathione peroxidase. Antioxid Redox Signal, v. 7, n. 1-2, p. 72-9, Jan-Feb 2005.

COOPER, S. J.; BOWDEN, G. T. Ultraviolet B regulation of transcription factor families: roles of nuclear factor-kappa B (NF-kappaB) and activator protein-1 (AP-1) in UVB-induced skin carcinogenesis. Curr Cancer Drug Targets, v. 7, n. 4, p. 325-34, Jun 2007.

CORSINI, E. et al. In vitro mechanism(s) of ultraviolet-induced tumor necrosis factor- $\alpha$ release in a human keratinocyte cell line. Photodermatology, Photoimmunology \& Photomedicine, v. 11, n. 3, p. 112-118, 1995.

COUSSENS, L. M.; WERB, Z. Inflammatory cells and cancer: think different! J Exp Med, v. 193, n. 6, p. F23-6, Mar 192001.

D'ARCHIVIO, M. et al. Polyphenols, dietary sources and bioavailability. Ann Ist Super Sanita, v. 43, n. 4, p. 348-61, 2007.

DAL BELO, S. E. et al. Skin penetration of epigallocatechin-3-gallate and quercetin from green tea and Ginkgo biloba extracts vehiculated in cosmetic formulations. Skin Pharmacol Physiol, v. 22, n. 6, p. 299-304, 2009.

DARGEL, R. Lipid peroxidation--a common pathogenetic mechanism? Exp Toxicol Pathol, v. 44, n. 4, p. 169-81, Aug 1992.

DAY, B. J. Catalase and glutathione peroxidase mimics. Biochemical Pharmacology, v. 77, n. 3, p. 285-296, 2/1/ 2009.

DEMACQ, C. et al. Inverse relationship between markers of nitric oxide formation and plasma matrix metalloproteinase-9 levels in healthy volunteers. Clin Chim Acta, v. 394, n. 12, p. 72-6, Aug 2008.

DENG, J.; CHENG, W.; YANG, G. A novel antioxidant activity index (AAU) for natural products using the DPPH assay. Food Chemistry, v. 125, n. 4, p. 1430-1435, 4/15/ 2011.

DI MAMBRO, V. M.; FONSECA, M. J. Assessment of physical and antioxidant activity stability, in vitro release and in vivo efficacy of formulations added with superoxide dismutase alone or in association with alpha-tocopherol. Eur J Pharm Biopharm, v. 66, n. 3, p. 451-9, Jun 2007.

DI MAMBRO, V. M.; FONSECA, M. J. V. Assays of physical stability and antioxidant activity of a topical formulation added with different plant extracts. Journal of Pharmaceutical and Biomedical Analysis, v. 37, n. 2, p. 287-295, 2/23/ 2005.

DICK, I. P.; SCOTT, R. C. Pig ear skin as an in-vitro model for human skin permeability. J Pharm Pharmacol, v. 44, n. 8, p. 640-5, Aug 1992.

DICKINSON, B. C.; CHANG, C. J. Chemistry and biology of reactive oxygen species in signaling or stress responses. Nat Chem Biol, v. 7, n. 8, p. 504-11, Aug 2011. 
DIZDAROGLU, M.; JARUGA, P. Mechanisms of free radical-induced damage to DNA. Free Radic Res, v. 46, n. 4, p. 382-419, Apr 2012.

DUTHIE, M. S.; KIMBER, I.; NORVAL, M. The effects of ultraviolet radiation on the human immune system. In: (Ed.). Br J Dermatol. England, v.140, 1999. p.995-1009.

ELIAS, P. M. Stratum corneum defensive functions: an integrated view. J Invest Dermatol, v. 125, n. 2, p. 183-200, Aug 2005.

F'GUYER, S.; AFAQ, F.; MUKHTAR, H. Photochemoprevention of skin cancer by botanical agents. Photodermatology Photoimmunology \& Photomedicine, v. 19, n. 2, p. 56-72, Apr 2003.

FARRUKH, M. R. et al. Oxidative stress mediated $\mathrm{Ca} 2+$ release manifests endoplasmic reticulum stress leading to unfolded protein response in UV-B irradiated human skin cells. Journal of Dermatological Science, v. 75, n. 1, p. 24-35, 7// 2014.

FIGUEIREDO, S. A. et al. In vitro and in vivo photoprotective/photochemopreventive potential of Garcinia brasiliensis epicarp extract. Journal of Photochemistry and Photobiology B: Biology, v. 131, n. 0, p. 65-73, 2/5/ 2014.

FILIP, A. et al. Photoprotective effects of two natural products on ultraviolet B-induced oxidative stress and apoptosis in SKH-1 mouse skin. J Med Food, v. 14, n. 7-8, p. 761-6, JulAug 2011. ISSN 1096-620x.

FISHER, G. J. et al. Ultraviolet irradiation increases matrix metalloproteinase- 8 protein in human skin in vivo. Journal of Investigative Dermatology, v. 117, n. 2, p. 219-226, Aug 2001.

FISHER GJ, KANG S, VARANI J, BATA-CSORGO Z, WAN Y, DATTA S, VOORHEES JJ. Mechanisms of photoaging and chronological skin aging. Arch Dermatol, v. 138, n. 11, p. 1462-70, Nov 2002.

FISHER, G. J.et al. Retinoic acid inhibits induction of c-Jun protein by ultraviolet radiation that occurs subsequent to activation of mitogen-activated protein kinase pathways in human skin in vivo. Journal of Clinical Investigation, v. 101, n. 6, p. 1432-1440, Mar 151998.

FILIP, G. A.; CLICHICI, S. Chemoprevention of Skin Cancer by Natural Compounds, Skin Cancers - Risk Factors, Prevention and Therapy. Prof Caterina La Porta (Ed.), November 14, 2011.

FLOHE, L. et al. Redox regulation of NF-kappa B activation. Free Radic Biol Med, v. 22, n. 6, p. 1115-26, 1997.

FONSECA, Y. M. Avaliação da atividade fotoquimiopreventiva do extrato de calêndula. 2010. 165p. Tese (Doutorado em Ciências) - Faculdade de Ciências Farmacêuticas de Ribeirão Preto, Universidade de São Paulo, Ribeirão Preto, 2010.

FONSECA, Y. M. et al. Protective effect of Calendula officinalis extract against UVBinduced oxidative stress in skin: Evaluation of reduced glutathione levels and matrix metalloproteinase secretion. Journal of Ethnopharmacology, v. 127, n. 3, p. 596-601, 2/17/ 2010. 
GARCIA-ROMAN, R. et al. The differential NF-kB modulation by S-adenosyl-Lmethionine, $\mathrm{N}$-acetylcysteine and quercetin on the promotion stage of chemical hepatocarcinogenesis. Free Radic Res, v. 42, n. 4, p. 331-43, Apr 2008.

GASPAR, L. R.; MAIA CAMPOS, P. M. Evaluation of the photostability of different UV filter combinations in a sunscreen. In: (Ed.). Int J Pharm. Netherlands, v.307, 2006. p.123-8.

GEIGER, P. G. et al. Lipid Peroxidation in Photodynamically Stressed Mammalian Cells: Use of Cholesterol Hydroperoxides as Mechanistic Reporters. Free Radical Biology and Medicine, v. 23, n. 1, p. 57-68, // 1997.

GERLACH, R. F. et al. Rapid separation of serum does not avoid artificially higher matrix metalloproteinase (MMP)-9 levels in serum versus plasma. Clin Biochem, v. 40, n. 1-2, p. 119-23, Jan 2007.

GILABERTE, Y. et al. Fotoprotección. Actas Dermo-Sifiliográficas, v. 94, n. 5, p. 271-293, // 2003.

GIROTTI, A. W. Translocation as a means of disseminating lipid hydroperoxide-induced oxidative damage and effector action. In: (Ed.). Free Radic Biol Med. United States, v.44, 2008.

GIROTTI, S. et al. Determination of superoxide dismutase in erythrocytes by a chemiluminescent assay. Talanta, v. 51, n. 4, p. 685-692, 4/3/ 2000.

GNIADECKI, R. Regulation of Keratinocyte Proliferation. General Pharmacology: The Vascular System, v. 30, n. 5, p. 619-622, 5// 1998.

GODIN, B.; TOUITOU, E. Transdermal skin delivery: predictions for humans from in vivo, ex vivo and animal models. In: (Ed.). Adv Drug Deliv Rev. Netherlands, v.59, 2007. p.115261.

GRONE, A. Keratinocytes and cytokines. Vet Immunol Immunopathol, v. 88, n. 1-2, p. 112, Sep 62002.

GUARATINI, T.; MEDEIROS, M. H. G.; COLEPICOLO, P. Antioxidants in the skin: Applications and evaluation of their efficacy. Quimica Nova, v. 30, n. 1, p. 206-213, Jan-Feb 2007.

GULCIN, I. et al. Polyphenol contents and antioxidant activity of lyophilized aqueous extract of propolis from Erzurum, Turkey. Food Chem Toxicol, v. 48, n. 8-9, p. 2227-38, Aug-Sep 2010.

GUPTA, N. et al. Cloning and identification of EDD gene from ultraviolet-irradiated HaCaT cells. Photodermatol Photoimmunol Photomed, v. 22, n. 6, p. 278-84, Dec 2006.

HADGRAFT, J. Skin deep. European Journal of Pharmaceutics and Biopharmaceutics, v. 58, n. 2, p. 291-299, 9// 2004.

HALLIDAY, G. M. Inflammation, gene mutation and photoimmunosuppression in response to UVR-induced oxidative damage contributes to photocarcinogenesis. Mutat Res, v. 571, n. 1-2, p. 107-20, Apr 12005. 
HANSON, K. M.; GRATTON, E.; BARDEEN, C. J. Sunscreen enhancement of UV-induced reactive oxygen species in the skin. Free Radic Biol Med, v. 41, n. 8, p. 1205-12, Oct 15 2006.

HECK, D. E. et al. Solar ultraviolet radiation as a trigger of cell signal transduction. Toxicology and Applied Pharmacology, v. 195, n. 3, p. 288-297, Mar 152004.

HERRLING, T.; JUNG, K.; FUCHS, J. Measurements of UV-generated free radicals/reactive oxygen species (ROS) in skin. Spectrochimica Acta Part A: Molecular and Biomolecular Spectroscopy, v. 63, n. 4, p. 840-845, 3/13/ 2006.

HIPPELI, S.; ELSTNER, E. F. Transition metal ion-catalyzed oxygen activation during pathogenic processes. FEBS Letters, v. 443, n. 1, p. 1-7, 1/22/ 1999.

HIRAYAMA, O. et al. Evaluation of antioxidant activity by chemiluminescence. Anal Biochem, v. 247, n. 2, p. 237-41, May 11997.

HISSIN, P. J.; HILF, R. A fluorometric method for determination of oxidized and reduced glutathione in tissues. Anal Biochem, v. 74, n. 1, p. 214-26, Jul 1976.

HO, J. N. et al. Protective effects of aucubin isolated from Eucommia ulmoides against UVB-induced oxidative stress in human skin fibroblasts. Biol Pharm Bull, v. 28, n. 7, p. 1244-8, Jul 2005.

HOJEROVA, J.; MEDOVCIKOVA, A.; MIKULA, M. Photoprotective efficacy and photostability of fifteen sunscreen products having the same label SPF subjected to natural sunlight. In: (Ed.). Int J Pharm. Netherlands: 2011 Elsevier B.V, v.408, 2011.

HSU, S. Green tea and the skin. J Am Acad Dermatol, v. 52, n. 6, p. 1049-59, Jun 2005.

HUANG, D.; OU, B.; PRIOR, R. L. The chemistry behind antioxidant capacity assays. J Agric Food Chem, v. 53, n. 6, p. 1841-56, Mar 232005.

HUBER, P. C.; ALMEIDA, W. P.; FÁTIMA, Â. D. Glutationa e enzimas relacionadas: papel biológico e importância em processos patológicos. Química Nova, v. 31, p. 1170-1179, 2008.

IGNAT, I.; VOLF, I.; POPA, V. I. A critical review of methods for characterisation of polyphenolic compounds in fruits and vegetables. Food Chemistry, v. 126, n. 4, p. 1821$1835,6 / 15 / 2011$.

ILLEL, B. Formulation for transfollicular drug administration: some recent advances. Crit Rev Ther Drug Carrier Syst, v. 14, n. 3, p. 207-19, 1997.

International Conference on Harmonization ( $\mathrm{ICH}$ ), ICH Harmonized tripartite guideline, Topic Q2B , Note for guidelines on Validation of Analytical Procedures: Methodology, 1996.

International Conference on Harmonization (ICH) of Technical Requirements for the registration of Pharmaceuticals for Human Use, Q3C: Impurities: Guideline for residual solvents. 1997. 
International Conference on Harmonization of Technical Requirements for Registration of Pharmaceuticals for Human Use (ICH). Guidance on genotoxicity testing and data interpretation for pharmaceuticals intended for human use, 2011.

ISHIDA, T.; SAKAGUCHI, I. Protection of human keratinocytes from UVB-induced inflammation using root extract of Lithospermum erythrorhizon. Biol Pharm Bull, v. 30, n. 5, p. 928-34, May 2007.

JANSSENS, S.; BEYAERT, R. Functional diversity and regulation of different interleukin-1 receptor-associated kinase (IRAK) family members. In: (Ed.). Mol Cell. United States, v.11, 2003. p.293-302.

JANTSCHKO, W. et al. Exploitation of the unusual thermodynamic properties of human myeloperoxidase in inhibitor design. Biochemical Pharmacology, v. 69, n. 8, p. 1149-1157, 2005.

JENKINS, G. Molecular mechanisms of skin ageing. Mech Ageing Dev, v. 123, n. 7, p. 80110, Apr 2002.

JEON, S. E. et al. Dietary supplementation of (+)-catechin protects against UVB-induced skin damage by modulating antioxidant enzyme activities. Photodermatol Photoimmunol Photomed, v. 19, n. 5, p. 235-41, Oct 2003.

JUNG, H.-Y. et al. Pinus densiflora extract protects human skin fibroblasts against UVBinduced photoaging by inhibiting the expression of MMPs and increasing type I procollagen expression. Toxicology Reports, v. 1, n. 0, p. 658-666, // 2014.

JUNG, S. K. et al. Myricetin suppresses UVB-induced wrinkle formation and MMP-9 expression by inhibiting Raf. Biochemical Pharmacology, v. 79, n. 10, p. 1455-1461, 5/15/ 2010.

JUNQUEIRA, L.C.; CARNEIRO, J. Histologia Básica. 10 ed. Rio de Janeiro: Guanabara Koogan, 2004. Pp 359-366.

KALLUNKI, T. et al. JNK2 CONTAINS A SPECIFICITY-DETERMINING REGION RESPONSIBLE FOR EFFICIENT C-JUN BINDING AND PHOSPHORYLATION. Genes \& Development, v. 8, n. 24, p. 2996-3007, Dec 151994.

KAMIJO, T. et al. Functional and physical interactions of the ARF tumor suppressor with p53 and Mdm2. Proceedings of the National Academy of Sciences of the United States of America, v. 95, n. 14, p. 8292-8297, Jul 71998.

KANITAKIS, J. Anatomy, histology and immunohistochemistry of normal human skin. Eur J Dermatol, v. 12, n. 4, p. 390-9; quiz 400-1, Jul-Aug 2002.

KATIYAR, S. K. et al. Inhibition of UVB-induced oxidative stress-mediated phosphorylation of mitogen-activated protein kinase signaling pathways in cultured human epidermal keratinocytes by green tea polyphenol (-)-epigallocatechin-3-gallate. Toxicology and Applied Pharmacology, v. 176, n. 2, p. 110-117, Oct 152001.

KATIYAR, S. K. et al. Green tea polyphenol (-)-epigallocatechin-3-gallate treatment of human skin inhibits ultraviolet radiation-induced oxidative stress. Carcinogenesis, v. 22, n. 2, p. 287-94, Feb 2001. 
KATIYAR, S. K.; MUKHTAR, H. Green tea polyphenol (-)-epigallocatechin-3-gallate treatment to mouse skin prevents UVB-induced infiltration of leukocytes, depletion of antigen-presenting cells, and oxidative stress. Journal of Leukocyte Biology, v. 69, n. 5, p. 719-726, May 2001.

KIM, H.-S. et al. Inhibition of UVB-induced wrinkle formation and MMP-9 expression by mangiferin isolated from Anemarrhena asphodeloides. European Journal of Pharmacology, v. 689 , n. $1-3$, p. $38-44,8 / 15 / 2012$.

KIM, H. H. et al. Augmentation of UV-induced skin wrinkling by infrared irradiation in hairless mice. Mechanisms of Ageing and Development, v. 126, n. 11, p. 1170-1177, Nov 2005.

KIM, H.H. Eicosapentaenoic acid inhibits UV-induced MMP-1 expression in human dermal fibroblasts. J Lipid Res, v. 46, n. 8, p. 1712-20, Aug 2005.

KIM, S.-H. et al. Gallic Acid Inhibits Histamine Release and Pro-inflammatory Cytokine Production in Mast Cells. Toxicological Sciences, v. 91, n. 1, p. 123-131, 2006.

KOCK, A. et al. Human keratinocytes are a source for tumor necrosis factor alpha: evidence for synthesis and release upon stimulation with endotoxin or ultraviolet light. J Exp Med, v. 172, n. 6, p. 1609-14, Dec 11990.

KOHEN, R. Skin antioxidants: their role in aging and in oxidative stress--new approaches for their evaluation. Biomed Pharmacother, v. 53, n. 4, p. 181-92, May 1999.

KONDO, S. The roles of keratinocyte-derived cytokines in the epidermis and their possible responses to UVA-irradiation. J Investig Dermatol Symp Proc, v. 4, n. 2, p. 177-83, Sep 1999.

KONDO, S. The roles of cytokines in photoaging. Journal of Dermatological Science, v. 23, Supplement 1, n. 0, p. S30-S36, 3// 2000.

KULlaVAniJAYA, P.; LIM, H. W. Photoprotection. Journal of the American Academy of Dermatology, v. 52, n. 6, p. 937-958, 6// 2005.

KUMAZAWA, S.; HAMASAKA, T.; NAKAYAMA, T. Antioxidant activity of propolis of various geographic origins. Food Chemistry, v. 84, n. 3, p. 329-339, 2// 2004.

KUPPER, T. S.; GROVES, R. W. The interleukin-1 axis and cutaneous inflammation. J Invest Dermatol, v. 105, n. 1 Suppl, p. 62s-66s, Jul 1995.

LAEMMLI, U. K. Cleavage of structural proteins during the assembly of the head of bacteriophage T4. Nature, v. 227, n. 5259, p. 680-5, Aug 151970.

LAHMANN, C. et al. Induction of mRNA for Matrix Metalloproteinase 1 and Tissue Inhibitor of Metalloproteinases 1 in Human Skin in vivo by Solar Simulated RadiationII. Photochemistry and Photobiology, v. 73, n. 6, p. 657-663, 2001.

LAPORNIK, B.; PROŠEK, M.; GOLC WONDRA, A. Comparison of extracts prepared from plant by-products using different solvents and extraction time. Journal of Food Engineering, v. 71, n. 2, p. 214-222, 11// 2005. 
LEONARDI, G. R.; GASPAR, L. R.; CAMPOS, P. M. B. G. M. Estudo da variação do pH da pele humana exposta à formulação cosmética acrescida ou não das vitaminas $\mathrm{A}, \mathrm{E}$ ou de ceramida, por metodologia não invasiva. Anais Brasileiros de Dermatologia, v. 77, p. 563$569,2002$.

LEVANG, A. K.; ZHAO, K.; SINGH, J. Effect of ethanol/propylene glycol on the in vitro percutaneous absorption of aspirin, biophysical changes and macroscopic barrier properties of the skin. International Journal of Pharmaceutics, v. 181, n. 2, p. 255-263, 4/30/ 1999.

LEVINE, A. J. p53, the cellular gatekeeper for growth and division. Cell, v. 88, n. 3, p. 323331, Feb 71997.

LEVITES, Y. et al. Attenuation of 6-hydroxydopamine (6-OHDA)-induced nuclear factorkappaB (NF- $\kappa \mathrm{B})$ activation and cell death by tea extracts in neuronal cultures. Biochemical Pharmacology, v. 63, n. 1, p. 21-29, 1/1/ 2002.

LI, J. et al. Chemical fingerprint and quantitative analysis for quality control of polyphenols extracted from pomegranate peel by HPLC. Food Chemistry, v. 176, n. 0, p. 7-11, 6/1/ 2015.

LI, R. et al. Phenolics and antioxidant activity of Saskatoon berry (Amelanchier alnifolia) pomace extract. J Med Food, v. 17, n. 3, p. 384-92, Mar 2014.

LIAO, K.; YIN, M. Individual and combined antioxidant effects of seven phenolic agents in human erythrocyte membrane ghosts and phosphatidylcholine liposome systems: importance of the partition coefficient. J Agric Food Chem, v. 48, n. 6, p. 2266-70, Jun 2000.

LIMA, A. R. et al. Avaliação in vitro da atividade antioxidante do extrato hidroalcoólico de folhas de bardana. Revista Brasileira de Farmacognosia, v. 16, n. 4, p. 531-536, 2006-12 2006.

LIN, C. C. et al. Tumor necrosis factor-alpha induces MMP-9 expression via p42/p44 MAPK, JNK, and nuclear factor-kappaB in A549 cells. Toxicol Appl Pharmacol, v. 229, n. 3, p. 386-98, Jun 152008.

LIU, X. et al. Quantitative analysis combined with chromatographic fingerprint for comprehensive evaluation of Danhong injection using HPLC-DAD. J Pharm Biomed Anal, v. 76, p. 70-4, Mar 252013.

LOTITO, S. B.; FRAGA, C. G. (+)-Catechin prevents human plasma oxidation. Free Radic Biol Med, v. 24, n. 3, p. 435-41, Feb 1998.

LU, Y. P. et al. Time course for early adaptive responses to ultraviolet B light in the epidermis of SKH-1 mice. Cancer Research, v. 59, n. 18, p. 4591-4602, Sep 151999.

LUO, D. et al. Effect of epigallocatechingallate on ultraviolet B-induced photo-damage in keratinocyte cell line. Am J Chin Med, v. 34, n. 5, p. 911-22, 2006.

MA, T. et al. Fingerprint analysis of Hawk-tea by high-performance liquid chromatography. Food Chemistry, v. 129, n. 2, p. 551-556, 11/15/ 2011.

MALDINI, M. et al. Screening of the topical anti-inflammatory activity of the bark of Acacia cornigera Willdenow, Byrsonima crassifolia Kunth, Sweetia panamensis Yakovlev and the leaves of Sphagneticola trilobata Hitchcock. J Ethnopharmacol, v. 122, n. 3, p. 430-3, Apr 212009. 
MAMMONE, T. et al. Successful separation of apoptosis and necrosis pathways in HaCaT keratinocyte cells induced by UVB irradiation. Cell Biol Toxicol, v. 16, n. 5, p. 293-302, 2000.

MANTENA, S. K.; KATIYAR, S. K. Grape seed proanthocyanidins inhibit UV-radiationinduced oxidative stress and activation of MAPK and NF-kappa B signaling in human epidermal keratinocytes. Free Radical Biology and Medicine, v. 40, n. 9, p. 1603-1614, May 12006.

MARNETT, L. J. Lipid peroxidation-DNA damage by malondialdehyde. Mutat Res, v. 424, n. 1-2, p. 83-95, Mar 81999.

MARQUELE, F. D. et al. Assessment of the antioxidant activities of Brazilian extracts of propolis alone and in topical pharmaceutical formulations. Journal of Pharmaceutical and Biomedical Analysis, v. 39, n. 3-4, p. 455-462, 9/15/ 2005.

MARQUELE-OLIVEIRA, F. et al. Development of topical functionalized formulations added with propolis extract: stability, cutaneous absorption and in vivo studies. Int J Pharm, v. 342, n. 1-2, p. 40-8, Sep 52007.

MARQUELE-OLIVEIRA, F. Desenvolvimento de formulações tópicos fotoquimioprotetoras contendo extrato de própolis: estudos de estabilidade, permeação e retenção cutânea in vitro e de eficácia in vivo. Tese de doutorado - Faculdade de ciências farmacêuticas de Ribeirão Preto, Universidade de São Paulo, Ribeirão Preto, 2007.

MARQUES, G. S. et al. Avaliação de procedimentos para quantificação espectrofotométrica de flavonoides totais em folhas de Bauhinia forficata Link. Química Nova, v. 35, p. 517-522, 2012.

MARTI-MESTRES, G. et al. The "in vitro" percutaneous penetration of three antioxidant compounds. Int J Pharm, v. 331, n. 1, p. 139-44, Feb 222007.

MARTÍNEZ-VÁZQUEZ, M. et al. Antimicrobial activity of Byrsonima crassifolia (L.) H.B.K. Journal of Ethnopharmacology, v. 66, n. 1, p. 79-82, 7// 1999.

MATSUMURA, Y.; ANANTHASWAMY, H. N. Toxic effects of ultraviolet radiation on the skin. Toxicology and Applied Pharmacology, v. 195, n. 3, p. 298-308, Mar 152004.

MAVERAKIS, E. et al. Light, including ultraviolet. J Autoimmun, v. 34, n. 3, p. J247-57, May 2010.

MEISTER, A.; ANDERSON, M. E. Glutathione. Annu Rev Biochem, v. 52, p. 711-60, 1983.

MELNIKOVA, V. O.; ANANTHASWAMY, H. N. Cellular and molecular events leading to the development of skin cancer. Mutation Research-Fundamental and Molecular Mechanisms of Mutagenesis, v. 571, n. 1-2, p. 91-106, Apr 12005.

MELONI, M.; NICOLAY, J. F. Dynamic monitoring of glutathione redox status in UV-B irradiated reconstituted epidermis: effect of antioxidant activity on skin homeostasis. Toxicol In Vitro, v. 17, n. 5-6, p. 609-13, Oct-Dec 2003.

MITTELSTADT, P. R. et al. Activating p38 MAPK: new tricks for an old kinase. Cell Cycle, v. 4, n. 9, p. 1189-92, Sep 2005. 
MOHAMED, M. A. et al. Protective effect of Disporum sessile D.Don extract against UVBinduced photoaging via suppressing MMP-1 expression and collagen degradation in human skin cells. J Photochem Photobiol B, v. 133, p. 73-9, Apr 52014.

MONGA, J. et al. Topical (+)-catechin emulsified gel prevents DMBA/TPA-induced squamous cell carcinoma of the skin by modulating antioxidants and inflammatory biomarkers in BALB/c mice. Food Funct, v. 5, n. 12, p. 3197-207, Dec 2014.

MONOSTORI, P. et al. Determination of glutathione and glutathione disulfide in biological samples: an in-depth review. J Chromatogr B Analyt Technol Biomed Life Sci, v. 877, n. 28, p. 3331-46, Oct 152009.

MOREIRA, D. D. L. et al. Substâncias fenólicas com atividade antioxidante de Pseudopiptadenia contorta (Leguminosae-Mimosoideae). Revista Brasileira de Farmacognosia, v. 12, n. Suppl. v. 1, p. 124-125, 20022002.

MOREL, I. et al. Antioxidant and iron-chelating activities of the flavonoids catechin, quercetin and diosmetin on iron-loaded rat hepatocyte cultures. Biochemical Pharmacology, v. 45, n. 1, p. 13-19, 1/7/ 1993.

MORLIERE, P. et al. UVA-induced lipid peroxidation in cultured human fibroblasts. In: (Ed.). Biochim Biophys Acta. Netherlands, v.1084, 1991.

MORLIERE, P.; MOYSAN, A.; TIRACHE, I. Action spectrum for UV-induced lipid peroxidation in cultured human skin fibroblasts. Free Radic Biol Med, v. 19, n. 3, p. 365-71, Sep 1995.

MOSER, K. et al. Passive skin penetration enhancement and its quantification in vitro. Eur J Pharm Biopharm, v. 52, n. 2, p. 103-12, Sep 2001.

MOURE, A. et al. Natural antioxidants from residual sources. Food Chemistry, v. 72, n. 2, p. $145-171,2 / / 2001$.

MUKHTAR, H.; ELMETS, C. A. Photocarcinogenesis: mechanisms, models and human health implications. Photochem Photobiol, v. 63, n. 4, p. 356-7, Apr 1996.

MULLER, K.; MEINEKE, V. Radiation-induced alterations in cytokine production by skin cells. In: (Ed.). Exp Hematol. Netherlands, v.35, 2007. p.96-104.

NAGASE, H.; VISSE, R.; MURPHY, G. Structure and function of matrix metalloproteinases and TIMPs. Cardiovasc Res, v. 69, n. 3, p. 562-73, Feb 152006.

NAKAO, M.; TAKIO, S.; ONO, K. Alkyl peroxyl radical-scavenging activity of catechins. Phytochemistry, v. 49, n. 8, p. 2379-2382, 12/20/ 1998.

NATARAJAN, V. T. et al. Multifaceted pathways protect human skin from UV radiation. Nat Chem Biol, v. 10, n. 7, p. 542-51, Jul 2014.

NICHOLS, J. A.; KATIYAR, S. K. Skin photoprotection by natural polyphenols: antiinflammatory, antioxidant and DNA repair mechanisms. Archives of Dermatological Research, v. 302, n. 2, p. 71-83, Mar 2010. 
NICOLAOU, A.; PILKINGTON, S. M.; RHODES, L. E. Ultraviolet-radiation induced skin inflammation: dissecting the role of bioactive lipids. Chem Phys Lipids, v. 164, n. 6, p. 53543, Sep 2011.

$\mathrm{OH}$, J. E. et al. A nuclear factor kappa B-derived inhibitor tripeptide inhibits UVB-induced photoaging process. Journal of Dermatological Science, v. 76, n. 3, p. 196-205, 12// 2014.

OHKAWA, H.; OHISHI, N.; YAGI, K. Assay for lipid peroxides in animal tissues by thiobarbituric acid reaction. Analytical Biochemistry, v. 95, n. 2, p. 351-358, 6// 1979.

ONOUE, S. et al. Induction of matrix metalloproteinase-9 secretion from human keratinocytes in culture by ultraviolet B irradiation. J Dermatol Sci, v. 33, n. 2, p. 105-11, Nov 2003.

PAGLiARA, A. et al. Evaluation and prediction of drug permeation. J Pharm Pharmacol, v. 51, n. 12, p. 1339-57, Dec 1999.

PALLELA, R.; NA-YOUNG, Y.; KIM, S. K. Anti-photoaging and photoprotective compounds derived from marine organisms. Mar Drugs, v. 8, n. 4, p. 1189-202, 2010.

PAREJO, I. et al. Evaluation of scavenging activity assessed by Co(II)/EDTA-induced luminol chemiluminescence and DPPH* (2,2-diphenyl-1-picrylhydrazyl) free radical assay. J Pharmacol Toxicol Methods, v. 44, n. 3, p. 507-12, Nov-Dec 2000.

PARK, H. M. et al. Extract of Punica granatum inhibits skin photoaging induced by UVB irradiation. Int J Dermatol, v. 49, n. 3, p. 276-82, Mar 2010.

PERAZA-SANCHEZ, S. R. et al. Leishmanicidal evaluation of extracts from native plants of the Yucatan peninsula. Fitoterapia, v. 78, n. 4, p. 315-8, Jun 2007.

PERES, P. S. et al. Photoaging and chronological aging profile: Understanding oxidation of the skin. Journal of Photochemistry and Photobiology B: Biology, v. 103, n. 2, p. 93-97, $5 / 3 / 2011$.

PEUS, D. et al. Vitamin E analog modulates UVB-induced signaling pathway activation and enhances cell survival. In: (Ed.). Free Radic Biol Med. United States, v.30, 2001. p.425-32.

PIETTA, P. G. Flavonoids as antioxidants. J Nat Prod, v. 63, n. 7, p. 1035-42, Jul 2000.

PILLAI, S.; ORESAJO, C.; HAYWARD, J. Ultraviolet radiation and skin aging: roles of reactive oxygen species, inflammation and protease activation, and strategies for prevention of inflammation-induced matrix degradation - a review. Int J Cosmet Sci, v. 27, n. 1, p. 1734, Feb 2005.

PINNELL, S. R. Cutaneous photodamage, oxidative stress, and topical antioxidant protection. Journal of the American Academy of Dermatology, v. 48, n. 1, p. 1-22, 1// 2003.

PIZZOFERRATO, A. et al. Cell culture methods for testing Biocompatibility. Clinical Materials, v. 15, n. 3, p. 173-190, // 1994.

POQUET, L.; CLIFFORD, M. N.; WILLIAMSON, G. Effect of dihydrocaffeic acid on UV irradiation of human keratinocyte HaCaT cells. Arch Biochem Biophys, v. 476, n. 2, p. 196204, Aug 152008. 
POTTS, R. Skin barrier: Principles of percutaneous absorption. Archives of Dermatology, v. 133, n. 7, p. 924-924, 1997.

POTTS, R. O.; GUY, R. H. Predicting skin permeability. Pharm Res, v. 9, n. 5, p. 663-9, May 1992.

RAHMANTO, A. S. et al. Cellular effects of photogenerated oxidants and long-lived, reactive, hydroperoxide photoproducts. Free Radical Biology and Medicine, v. 49, n. 10, p. $1505-1515,11 / 30 / 2010$.

RAMIRO, E. et al. Flavonoids from Theobroma cacao down-regulate inflammatory mediators. J Agric Food Chem, v. 53, n. 22, p. 8506-11, Nov 2005.

RAUT, S. et al. Lecithin organogel: A unique micellar system for the delivery of bioactive agents in the treatment of skin aging. Acta Pharmaceutica Sinica B, v. 2, n. 1, p. 8-15, 2/10/ 2012.

RAY, P. D.; HUANG, B.-W.; TSUJI, Y. Reactive oxygen species (ROS) homeostasis and redox regulation in cellular signaling. Cellular Signalling, v. 24, n. 5, p. 981-990, 5// 2012.

RIBANI, M. et al. Validação em métodos cromatográficos e eletroforéticos. Química Nova, v. 27, p. 771-780, 2004.

RICE-EVANS, C. Implications of the mechanisms of action of tea polyphenols as antioxidants in vitro for chemoprevention in humans. Proc Soc Exp Biol Med, v. 220, n. 4, p. 262-6, Apr 1999.

RICE-EVANS, C.; MILLER, N.; PAGANGA, G. Antioxidant properties of phenolic compounds. Trends in Plant Science, v. 2, n. 4, p. 152-159, 4// 1997.

RITTIE, L.; FISHER, G. J. UV-light-induced signal cascades and skin aging. Ageing Res Rev, v. 1, n. 4, p. 705-20, Sep 2002.

ROBAK, J.; GRYGLEWSKI, R. J. Flavonoids are scavengers of superoxide anions. Biochemical Pharmacology, v. 37, n. 5, p. 837-841, 3/1/ 1988.

RODRIGUES, T. et al. Thioridazine interacts with the membrane of mitochondria acquiring antioxidant activity toward apoptosis--potentially implicated mechanisms. Br J Pharmacol, v. 136, n. 1, p. 136-42, May 2002.

RUBIO, L. et al. Barrier function of intact and impaired skin: percutaneous penetration of caffeine and salicylic acid. Int J Dermatol, v. 50, n. 7, p. 881-9, Jul 2011.

SALIOU, C. et al. Solar ultraviolet-induced erythema in human skin and nuclear factorkappa-B-dependent gene expression in keratinocytes are modulated by a French maritime pine bark extract. Free Radic Biol Med, v. 30, n. 2, p. 154-60, Jan 152001.

SANDER, C. S. et al. Role of oxidative stress and the antioxidant network in cutaneous carcinogenesis. International Journal of Dermatology, v. 43, n. 5, p. 326-335, May 2004.

SANDER, C. S. et al. Photoaging is associated with protein oxidation in human skin in vivo. J Invest Dermatol, v. 118, n. 4, p. 618-25, Apr 2002.

SANTA-MARÍA, C. et al. Protection against free radicals (UVB irradiation) of a watersoluble enzymatic extract from rice bran. Study using human keratinocyte monolayer and 
reconstructed human epidermis. Food and Chemical Toxicology, v. 48, n. 1, p. 83-88, 1// 2010.

SCANDAliOS, J. G. Oxygen Stress and Superoxide Dismutases. Plant Physiology, v. 101, n. 1, p. 7-12, 1993.

SEKKAT, N.; KALIA, Y. N.; GUY, R. H. Biophysical study of porcine ear skin in vitro and its comparison to human skin in vivo. J Pharm Sci, v. 91, n. 11, p. 2376-81, Nov 2002.

SERPONE, N.; DONDI, D.; ALBINI, A. Inorganic and organic UV filters: Their role and efficacy in sunscreens and suncare products. Inorganica Chimica Acta, v. 360, n. 3, p. 794$802,2 / 15 / 2007$.

SEYOUM, A.; ASRES, K.; EL-FIKY, F. K. Structure-radical scavenging activity relationships of flavonoids. Phytochemistry, v. 67, n. 18, p. 2058-70, Sep 2006.

SHAH, H.; RAWAL MAHAJAN, S. Photoaging: New insights into its stimulators, complications, biochemical changes and therapeutic interventions. Biomedicine \& Aging Pathology, v. 3, n. 3, p. 161-169, 7// 2013.

SHINDO, Y. et al. Dose-response effects of acute ultraviolet irradiation on antioxidants and molecular markers of oxidation in murine epidermis and dermis. J Invest Dermatol, v. 102, n. 4, p. 470-5, Apr 1994.

SHINDO, Y.; WITT, E.; PACKER, L. Antioxidant defense mechanisms in murine epidermis and dermis and their responses to ultraviolet light. J Invest Dermatol, v. 100, n. 3, p. 260-5, Mar 1993.

SIERENS, J. et al. Effect of phytoestrogen and antioxidant supplementation on oxidative DNA damage assessed using the comet assay. Mutat Res, v. 485, n. 2, p. 169-76, Mar 7 2001.

SILVA, E. M.; ROGEZ, H.; LARONDELLE, Y. Optimization of extraction of phenolics from Inga edulis leaves using response surface methodology. Separation and Purification Technology, v. 55, n. 3, p. 381-387, 7/1/ 2007.

SILVA, E. M. et al. Antioxidant activities and polyphenolic contents of fifteen selected plant species from the Amazonian region. Food Chemistry, v. 101, n. 3, p. 1012-1018, // 2007.

SINGLETON, V.L.; ORTHOFER, R.; LAMUELA-RAVENTÓS, R.M. Analysis of Total Phenols and Other Oxidation Substrates and Antioxidants by Means of Folin-Ciocalteu Reagent. Methods in Enzymology, San Diego, v. 299, p. 152-172, 1999.

SIVAMANI, R. K.; MAIBACH, H. I. Fruits are rich in antioxidants and ripe for topical therapy. Journal of Dermatological Treatment, v. 20, n. 4, p. 186-189, 2009.

SMITH, M. L.; FORNACE, A. J. p53-mediated protective responses to UV irradiation. Proceedings of the National Academy of Sciences of the United States of America, v. 94, n. 23, p. 12255-12257, Nov 111997.

SNOEK-VAN BEURDEN, P. A.; VON DEN HOFF, J. W. Zymographic techniques for the analysis of matrix metalloproteinases and their inhibitors. In: (Ed.). Biotechniques. United States, v.38, 2005. p.73-83. 
SONG, X. Z.; BI, Z. G.; XU, A. E. Green tea polyphenol epigallocatechin-3-gallate inhibits the expression of nitric oxide synthase and generation of nitric oxide induced by ultraviolet $\mathrm{B}$ in HaCaT cells. Chin Med J (Engl), v. 119, n. 4, p. 282-7, Feb 202006.

SOOBRATTEE, M. A. et al. Phenolics as potential antioxidant therapeutic agents: Mechanism and actions. Mutation Research/Fundamental and Molecular Mechanisms of Mutagenesis, v. 579, n. 1-2, p. 200-213, 11/11/ 2005.

SOUZA, J. N. S., Etude des propriétés antioxydantes in vitro d'extraits de feuilles de Byrsonima crassifolia et Inga edulis et caractérisation partielle des composés phénoliques. (Promoteurs : Larondelle Y., Rogez H.) 2007.

SOUZA, J. N. S. et al. Antioxidant capacity of four polyphenol-rich Amazonian plant extracts: A correlation study using chemical and biological in vitro assays. Food Chemistry, v. 106, n. 1, p. 331-339, Jan 12008.

SUN, H. B.; MALACINSKI, G. M.; YOKOTA, H. Promoter competition assay for analyzing gene regulation in joint tissue engineering. Front Biosci, v. 7, p. a169-74, Aug 12002.

SURH, Y.-J. et al. Molecular mechanisms underlying chemopreventive activities of antiinflammatory phytochemicals: down-regulation of COX-2 and iNOS through suppression of NF- $\kappa \mathrm{B}$ activation. Mutation Research/Fundamental and Molecular Mechanisms of Mutagenesis, v. 480-481, n. 0, p. 243-268, 9/1/ 2001.

SVOBODOVA, A.; VOSTALOVA, J. Solar radiation induced skin damage: Review of protective and preventive options. International Journal of Radiation Biology, v. 86, n. 12, p. $999-1030$, Dec 2010.

SVOBODOVA, A.; WALTEROVA, D.; VOSTALOVA, J. Ultraviolet light induced alteration to the skin. Biomed Pap Med Fac Univ Palacky Olomouc Czech Repub, v. 150, n. 1, p. 25-38, Jul 2006.

SVOBODOVA, A. et al. Flavonolignans from Silybum marianum moderate UVA-induced oxidative damage to HaCaT keratinocytes. J Dermatol Sci, v. 48, n. 3, p. 213-24, Dec 2007.

TAN, F. et al. Comparative evaluation of the cytotoxicity sensitivity of six fish cell lines to four heavy metals in vitro. Toxicol In Vitro, v. 22, n. 1, p. 164-70, Feb 2008.

TANAKA, K. et al. Prevention of the ultraviolet B-mediated skin photoaging by a nuclear factor kappaB inhibitor, parthenolide. J Pharmacol Exp Ther, v. 315, n. 2, p. 624-30, Nov 2005.

TANAKA, K. et al. Magnolia ovovata extract and its active component magnolol prevent skin photoaging via inhibition of nuclear factor kappaB. Eur J Pharmacol, v. 565, n. 1-3, p. 212-9, Jun 222007.

TERUI, T.; OKUYAMA, R.; TAGAMI, H. Molecular events occurring behind ultravioletinduced skin inflammation. Curr Opin Allergy Clin Immunol, v. 1, n. 5, p. 461-7, Oct 2001.

THOMAS-AHNER, J. M. et al. Gender differences in UVB-induced skin carcinogenesis, inflammation, and DNA damage. Cancer Research, v. 67, n. 7, p. 3468-3474, Apr 12007.

TRUSH, M. A.; EGNER, P. A.; KENSLER, T. W. Myeloperoxidase as a biomarker of skin irritation and inflammation. Food and Chemical Toxicology, v. 32, n. 2, p. 143-147, 1994. 
UITTO, J. The role of elastin and collagen in cutaneous aging: intrinsic aging versus photoexposure. J Drugs Dermatol, v. 7, n. 2 Suppl, p. s12-6, Feb 2008.

ULLRICH, S. E. The role of epidermal cytokines in the generation of cutaneous immune reactions and ultraviolet radiation-induced immune suppression. Photochem Photobiol, v. 62, n. 3, p. 389-401, Sep 1995.

VALKO, M. et al. Free radicals and antioxidants in normal physiological functions and human disease. Int J Biochem Cell Biol, v. 39, n. 1, p. 44-84, 2007.

VAN ACKER, S. A. et al. Structural aspects of antioxidant activity of flavonoids. Free Radic Biol Med, v. 20, n. 3, p. 331-42, 1996.

VARANI, J. et al. Inhibition of Type I Procollagen Synthesis by Damaged Collagen in Photoaged Skin and by Collagenase-Degraded Collagen in Vitro. The American Journal of Pathology, v. 158, n. 3, p. 931-942, 3// 2001.

VARVARESOU, A. Percutaneous absorption of organic sunscreens. Journal of Cosmetic Dermatology, v. 5, n. 1, p. 53-57, 2006.

VAYALIL, P. K.; ELMETS, C. A.; KATIYAR, S. K. Treatment of green tea polyphenols in hydrophilic cream prevents UVB-induced oxidation of lipids and proteins, depletion of antioxidant enzymes and phosphorylation of MAPK proteins in SKH-1 hairless mouse skin. Carcinogenesis, v. 24, n. 5, p. 927-36, May 2003.

VERSCHOOTEN, L. et al. New strategies of photoprotection. Photochemistry and Photobiology, v. 82, n. 4, p. 1016-1023, Jul-Aug 2006.

VERSTRAETEN, S. V. et al. Flavan-3-ols and procyanidins protect liposomes against lipid oxidation and disruption of the bilayer structure. Free Radical Biology and Medicine, v. 34, n. 1, p. 84-92, 1/1/ 2003.

VICENTINI, F. T. et al. Quercetin in w/o microemulsion: in vitro and in vivo skin penetration and efficacy against UVB-induced skin damages evaluated in vivo. Eur J Pharm Biopharm, v. 69, n. 3, p. 948-57, Aug 2008.

VICENTINI, F. T. M. D. C. et al. Assessment of in vitro methodologies to determine topical and transdermal delivery of the flavonoid quercetin. Brazilian Journal of Pharmaceutical Sciences, v. 45, p. 357-364, 2009.

VICENTINI F. T.. M C.; GEORGETTI S. R.; JABOR J. R.; CARIS J. A.; BENTLEY M. V. L. B.; FONSECA M. J. V. Photostability of Quercetin under Exposure to UV irradiation. Latin American Journal of Pharmacy,p.119-124, 2007

VICENTINI, F.T.M.C.; CASAGRANDE, R.; GEORGETTI, S.R.; BENTLEY, M.V.L.B.; FONSECA, M.J.V. Influence of vehicle on antioxidant activity of quercetin: A liquid crystalline formulation. Latin American Journal of Pharmacy. v.26, p.805-810, 2007b

WEINSTOCK, M. A. Do sunscreens increase or decrease melanoma risk: an epidemiologic evaluation. J Investig Dermatol Symp Proc, v. 4, n. 1, p. 97-100, Sep 1999.

WERTZ, P. W. Current understanding of skin biology pertinent to skin penetration: skin biochemistry. Skin Pharmacol Physiol, v. 26, n. 4-6, p. 217-26, 2013. 
WESOŁOWSKA, O. et al. Interaction of the chemopreventive agent resveratrol and its metabolite, piceatannol, with model membranes. Biochimica et Biophysica Acta (BBA) Biomembranes, v. 1788, n. 9, p. 1851-1860, 9// 2009.

WHITE, E. Life, death, and the pursuit of apoptosis. Genes \& Development, v. 10, n. 1, p. 115, Jan 11996.

WICKENS, A. P. Ageing and the free radical theory. Respir Physiol, v. 128, n. 3, p. 379-91, Nov 152001.

WISEMAN, S.; MULDER, T.; RIETVELD, A. Tea flavonoids: bioavailability in vivo and effects on cell signaling pathways in vitro. Antioxid Redox Signal, v. 3, n. 6, p. 1009-21, Dec 2001.

WITTGEN, H. G.; VAN KEMPEN, L. C. Reactive oxygen species in melanoma and its therapeutic implications. Melanoma Res, v. 17, n. 6, p. 400-9, Dec 2007.

WOOD, L. C. et al. Barrier disruption stimulates interleukin-1 alpha expression and release from a pre-formed pool in murine epidermis. J Invest Dermatol, v. 106, n. 3, p. 397-403, Mar 1996.

WRIGHT, T. I.; SPENCER, J. M.; FLOWERS, F. P. Chemoprevention of nonmelanoma skin cancer. J Am Acad Dermatol, v. 54, n. 6, p. 933-46; quiz 947-50, Jun 2006.

WU, J. H. et al. Phenolic antioxidants from the heartwood of Acacia confusa. Journal of Agricultural and Food Chemistry, v. 53, n. 15, p. 5917-5921, Jul 272005.

WU, W.-B. et al. (+)-Catechin prevents ultraviolet B-induced human keratinocyte death via inhibition of JNK phosphorylation. Life Sciences, v. 79, n. 8, p. 801-807, 7/17/ 2006.

XIA, J. et al. UV-induced NF-kappaB activation and expression of IL-6 is attenuated by (-)epigallocatechin-3-gallate in cultured human keratinocytes in vitro. Int J Mol Med, v. 16, n. 5, p. 943-50, Nov 2005.

XIA, Y.; ZWEIER, J. L. Measurement of Myeloperoxidase in Leukocyte-Containing Tissues. Analytical Biochemistry, v. 245, n. 1, p. 93-96, 1997.

XU, Y. R.; FISHER, G. J. Ultraviolet (UV) light irradiation induced signal transduction in skin photoaging. Journal of Dermatological Science, p. S1-S8, Dec 2005.

YANG, C. S.; MALIAKAL, P.; MENG, X. Inhibition of carcinogenesis by tea. Annu Rev Pharmacol Toxicol, v. 42, p. 25-54, 2002.

YILMAZ, Y.; TOLEDO, R. T. Major flavonoids in grape seeds and skins: antioxidant capacity of catechin, epicatechin, and gallic acid. J Agric Food Chem, v. 52, n. 2, p. 255-60, Jan 282004.

YOUNG, A. R. Acute effects of UVR on human eyes and skin. Prog Biophys Mol Biol, v. 92, n. 1, p. 80-5, Sep 2006.

YU, B. P.; YANG, R. Critical evaluation of the free radical theory of aging. A proposal for the oxidative stress hypothesis. Ann N Y Acad Sci, v. 786, p. 1-11, Jun 151996.

ZAMBETTI, G. P.; LEVINE, A. J. A COMPARISON OF THE BIOLOGICAL-ACTIVITIES OF WILD-TYPE AND MUTANT-P53. Faseb Journal, v. 7, n. 10, p. 855-865, Jul 1993. 
ZHANG, J. et al. Inhibition of lipid oxidation by phenolic antioxidants in relation to their physicochemical properties. Pharmacologyonline v. 1, p. 180-189 (2007).

ZHOU, B. R. et al. Baicalin protects human skin fibroblasts from ultraviolet A radiationinduced oxidative damage and apoptosis. Free Radic Res, v. 46, n. 12, p. 1458-71, Dec 2012.

ZOUBOULIS, C. C.; MAKRANTONAKI, E. Clinical aspects and molecular diagnostics of skin aging. Clin Dermatol, v. 29, n. 1, p. 3-14, Jan-Feb 2011. 